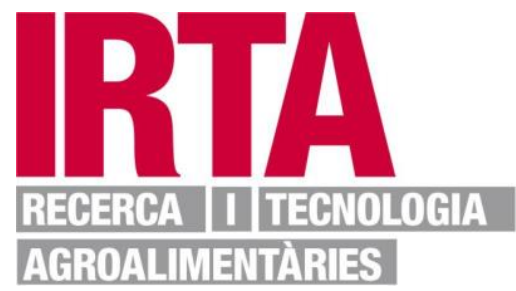

This document is a postprint version of an article published in Computers and Electronics in Agriculture (C) Elsevier after peer review. To access the final edited and published work see https://doi.org/10.1016/j.compag.2018.02.016 


\title{
Deep Learning in Agriculture: A Survey
}

\author{
Andreas Kamilaris ${ }^{1}$ and Francesc X. Prenafeta-Boldú \\ Institute for Food and Agricultural Research and Technology (IRTA)
}

\begin{abstract}
Deep learning constitutes a recent, modern technique for image processing and data analysis, with promising results and large potential. As deep learning has been successfully applied in various domains, it has recently entered also the domain of agriculture. In this paper, we perform a survey of 40 research efforts that employ deep learning techniques, applied to various agricultural and food production challenges. We examine the particular agricultural problems under study, the specific models and frameworks employed, the sources, nature and pre-processing of data used, and the overall performance achieved according to the metrics used at each work under study. Moreover, we study comparisons of deep learning with other existing popular techniques, in respect to differences in classification or regression performance. Our findings indicate that deep learning provides high accuracy, outperforming existing commonly used image processing techniques.
\end{abstract}

Keywords: Deep learning, Agriculture, Survey, Convolutional Neural Networks, Recurrent Neural Networks, Smart Farming, Food Systems.

${ }^{1}$ Corresponding Author. Email: andreas.kamilaris@irta.cat 


\section{Introduction}

Smart farming (Tyagi, 2016) is important for tackling the challenges of agricultural production in terms of productivity, environmental impact, food security and sustainability (Gebbers \& Adamchuk, 2010). As the global population has been continuously increasing (Kitzes, et al., 2008), a large increase on food production must be achieved (FAO, 2009), maintaining at the same time availability and high nutritional quality across the globe, protecting the natural ecosystems by using sustainable farming procedures. To address these challenges, the complex, multivariate and unpredictable agricultural ecosystems need to be better understood by monitoring, measuring and analyzing continuously various physical aspects and phenomena. This implies analysis of big agricultural data (Kamilaris, Kartakoullis, \& Prenafeta-Boldú, A review on the practice of big data analysis in agriculture, 2017), and the use of new information and communication technologies (ICT) (Kamilaris, Gao, Prenafeta-Boldú, \& Ali, 2016), both for short-scale crop/farm management as well as for larger-scale ecosystems' observation, enhancing the existing tasks of management and decision/policy making by context, situation and location awareness. Larger-scale observation is facilitated by remote sensing (Bastiaanssen, Molden, \& Makin, 2000), performed by means of satellites, airplanes and unmanned aerial vehicles (UAV) (i.e. drones), providing wide-view snapshots of the agricultural environments. It has several advantages when applied to agriculture, being a well-known, non-destructive method to collect information about earth features while data may be obtained systematically over large geographical areas.

A large subset of the volume of data collected through remote sensing involve images. Images constitute, in many cases, a complete picture of the agricultural environments and could address a variety of challenges (Liaghat \& Balasundram, 2010), (Ozdogan, Yang, Allez, \& Cervantes, 2010). Hence, imaging analysis is an important research area in the agricultural domain and intelligent data analysis techniques are being used for image 
identification/classification, anomaly detection etc., in various agricultural applications (Teke, Deveci, Haliloğlu, Gürbüz, \& Sakarya, 2013), (Saxena \& Armstrong, 2014), (Singh, Ganapathysubramanian, Singh, \& Sarkar, 2016). The most popular techniques and applications are presented in Appendix I, together with the sensing methods employed to acquire the images. From existing sensing methods, the most common one is satellitebased, using multi-spectral and hyperspectral imaging. Synthetic aperture radar (SAR), thermal and near infrared (NIR) cameras are being used in a lesser but increasing extent (Ishimwe, Abutaleb, \& Ahmed, 2014), while optical and X-ray imaging are being applied in fruit and packaged food grading. The most popular techniques used for analyzing images include machine learning (ML) (K-means, support vector machines (SVM), artificial neural networks (ANN) amongst others), linear polarizations, wavelet-based filtering, vegetation indices (NDVI) and regression analysis (Saxena \& Armstrong, 2014), (Singh, Ganapathysubramanian, Singh, \& Sarkar, 2016).

Besides the aforementioned techniques, a new one which is recently gaining momentum is deep learning (DL) (LeCun, Bengio, \& Hinton, 2015), (LeCun \& Bengio, 1995). DL belongs to the machine learning computational field and is similar to ANN. However, DL is about "deeper" neural networks that provide a hierarchical representation of the data by means of various convolutions. This allows larger learning capabilities and thus higher performance and precision. A brief description of DL is attempted in Section 3. The motivation for preparing this survey stems from the fact that $\mathrm{DL}$ in agriculture is a recent, modern and promising technique with growing popularity, while advancements and applications of $\mathrm{DL}$ in other domains indicate its large potential. The fact that today there exists at least 40 research efforts employing $\mathrm{DL}$ to address various agricultural problems with very good results, encouraged the authors to prepare this survey. To the authors' knowledge, this is the first such survey in the agricultural domain, while a small number of more general surveys do exist (Deng \& Yu, 2014), (Wan, et al., 2014), (Najafabadi, et al., 
2015), covering related work in DL in other domains.

\section{Methodology}

The bibliographic analysis in the domain under study involved two steps: a) collection of related work and b) detailed review and analysis of this work. In the first step, a keywordbased search for conference papers or journal articles was performed from the scientific databases IEEE Xplore and ScienceDirect, and from the web scientific indexing services Web of Science and Google Scholar. As search keywords, we used the following query: ["deep learning"] AND ["agriculture" OR "farming"]

In this way, we filtered out papers referring to DL but not applied to the agricultural domain. From this effort, 47 papers had been initially identified. Restricting the search for papers with appropriate application of the DL technique and meaningful findings ${ }^{2}$, the initial number of papers reduced to 40 .

In the second step, the 40 papers selected from the previous step were analyzed one-byone, considering the following research questions:

1. Which was the agricultural- or food-related problem they addressed?

2. Which was the general approach and type of DL-based models employed?

3. Which sources and types of data had been used?

4. Which were the classes and labels as modeled by the authors? Were there any variations among them, observed by the authors?

5. Any pre-processing of the data or data augmentation techniques used?

6. Which has been the overall performance depending on the metric adopted?

7. Did the authors test the performance of their models on different datasets?

8. Did the authors compare their approach with other techniques and, if yes, which was the difference in performance?

Our main findings are presented in Section 4 and the detailed information per paper is

\footnotetext{
${ }^{2}$ A small number of papers claimed of using DL in some agricultural-related application, but they did not show any results nor provided performance metrics that could indicate the success of the technique used.
} 
listed in Appendix II.

\section{Deep Learning}

DL extends classical ML by adding more "depth" (complexity) into the model as well as transforming the data using various functions that allow data representation in a hierarchical way, through several levels of abstraction (Schmidhuber, 2015), (LeCun \& Bengio, 1995). A strong advantage of $D L$ is feature learning, i.e. the automatic feature extraction from raw data, with features from higher levels of the hierarchy being formed by the composition of lower level features (LeCun, Bengio, \& Hinton, 2015). DL can solve more complex problems particularly well and fast, because of more complex models used, which allow massive parallelization (Pan \& Yang, 2010). These complex models employed in DL can increase classification accuracy or reduce error in regression problems, provided there are adequately large datasets available describing the problem. DL consists of various different components (e.g. convolutions, pooling layers, fully connected layers, gates, memory cells, activation functions, encode/decode schemes etc.), depending on the network architecture used (i.e. Unsupervised Pre-trained Networks, Convolutional Neural Networks, Recurrent Neural Networks, Recursive Neural Networks). The highly hierarchical structure and large learning capacity of DL models allow them to perform classification and predictions particularly well, being flexible and adaptable for a wide variety of highly complex (from a data analysis perspective) challenges (Pan \& Yang, 2010). Although DL has met popularity in numerous applications dealing with raster-based data (e.g. video, images), it can be applied to any form of data, such as audio, speech, and natural language, or more generally to continuous or point data such as weather data (Sehgal, et al., 2017), soil chemistry (Song, et al., 2016) and population data (Demmers T. G., Cao, Parsons, Gauss, \& Wathes, 2012). An example DL architecture is displayed in Figure 1, illustrating CaffeNet (Jia, et al., 2014), an example of a convolutional neural network, combining convolutional and fully connected (dense) layers. 

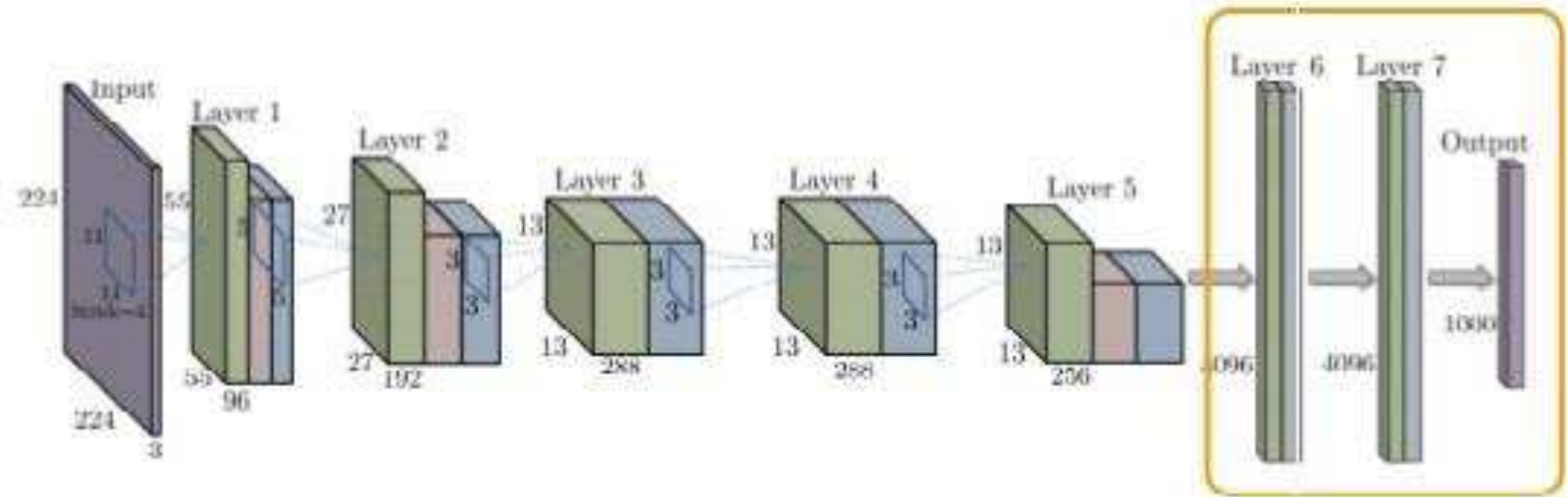

fully connected

layers

Figure 1: CaffeNet, an example CNN architecture. Source: (Sladojevic, Arsenovic, Anderla, Culibrk, \& Stefanovic, 2016)

Convolutional Neural Networks (CNN) constitute a class of deep, feed-forward ANN, and they appear in numerous of the surveyed papers as the technique used (17 papers, $42 \%$ ). As the figure shows, various convolutions are performed at some layers of the network, creating different representations of the learning dataset, starting from more general ones at the first larger layers, becoming more specific at the deeper layers. The convolutional layers act as feature extractors from the input images whose dimensionality is then reduced by the pooling layers. The convolutional layers encode multiple lower-level features into more discriminative features, in a way that is spatially context-aware. They may be understood as banks of filters that transform an input image into another, highlighting specific patterns. The fully connected layers, placed in many cases near the output of the model, act as classifiers exploiting the high-level features learned to classify input images in predefined classes or to make numerical predictions. They take a vector as input and produce another vector as output. An example visualization of leaf images after each processing step of the CaffeNet CNN, at a problem of identifying plant diseases, is depicted in Figure 2. We can observe that after each processing step, the particular elements of the image that reveal the indication of a disease become more evident, especially at the final step (Pool5). 

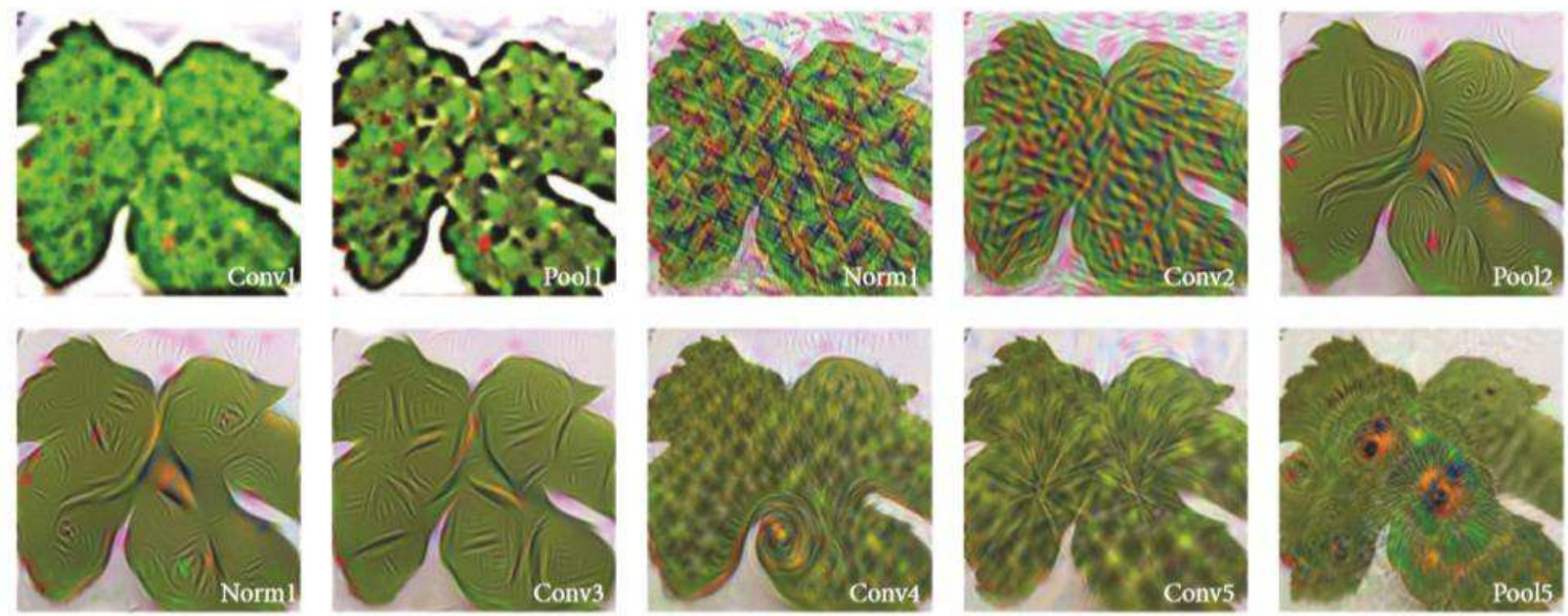

Figure 2: Visualization of the output layers images after each processing step of the CaffeNet CNN (i.e. convolution, pooling, normalization) at a plant disease identification problem based on leaf images. Source: (Sladojevic, Arsenovic, Anderla, Culibrk, \& Stefanovic, 2016)

One of the most important advantages of using $\mathrm{DL}$ in image processing is the reduced need of feature engineering (FE). Previously, traditional approaches for image classification tasks had been based on hand-engineered features, whose performance affected heavily the overall results. FE is a complex, time-consuming process which needs to be altered whenever the problem or the dataset changes. Thus, FE constitutes an expensive effort that depends on experts' knowledge and does not generalize well (Amara, Bouaziz, \& Algergawy, 2017). On the other hand, DL does not require FE, locating the important features itself through training.

A disadvantage of $\mathrm{DL}$ is the generally longer training time. However, testing time is generally faster than other methods ML-based methods (Chen, Lin, Zhao, Wang, \& Gu, 2014). Other disadvantages include problems that might occur when using pre-trained models on datasets that are small or significantly different, optimization issues because of the models' complexity, as well as hardware restrictions.

In Section 5, we discuss over advantages and disadvantages of DL as they reveal through the surveyed papers. 


\subsection{Available Architectures, Datasets and Tools}

There exist various successful and popular architectures, which researchers may use to start building their models instead of starting from scratch. These include AlexNet (Krizhevsky, Sutskever, \& Hinton, 2012), CaffeNet (Jia, et al., 2014) (displayed in Figure

1), VGG (Simonyan \& Zisserman, 2014), GoogleNet (Szegedy, et al., 2015) and InceptionResNet (Szegedy, loffe, Vanhoucke, \& Alemi, 2017), among others. Each architecture has different advantages and scenarios where it is more appropriate to be used (Canziani, Paszke, \& Culurciello, 2016). It is also worth noting that almost all of the aforementioned models come along with their weights pre-trained, which means that their network had been already trained by some dataset and has thus learned to provide accurate classification for some particular problem domain (Pan \& Yang, 2010). Common datasets used for pre-training DL architectures include ImageNet (Deng, et al., 2009) and PASCAL VOC (PASCAL VOC Project, 2012) (see also Appendix III).

Moreover, there exist various tools and platforms allowing researchers to experiment with DL (Bahrampour, Ramakrishnan, Schott, \& Shah, 2015). The most popular ones are Theano, TensorFlow, Keras (which is an application programmer's interface on top of Theano and TensorFlow), Caffe, PyTorch, TFLearn, Pylearn2 and the Deep Learning Matlab Toolbox. Some of these tools (i.e. Theano, Caffe) incorporate popular architectures such as the ones mentioned above (i.e. AlexNet, VGG, GoogleNet), either as libraries or classes. For a more elaborate description of the DL concept and its applications, the reader could refer to existing bibliography (Schmidhuber, 2015), (Deng \& Yu, 2014), (Wan, et al., 2014), (Najafabadi, et al., 2015), (Canziani, Paszke, \& Culurciello, 2016), (Bahrampour, Ramakrishnan, Schott, \& Shah, 2015).

\section{Deep Learning Applications in Agriculture}

In Appendix II, we list the 40 identified relevant works, indicating the agricultural-related 
research area, the particular problem they address, DL models and architectures implemented, sources of data used, classes and labels of the data, data pre-processing and/or augmentation employed, overall performance achieved according to the metrics adopted, as well as comparisons with other techniques, wherever available.

\subsection{Areas of Use}

Sixteen areas have been identified in total, with the popular ones being identification of weeds (5 papers), land cover classification (4 papers), plant recognition (4 papers), fruits counting (4 papers) and crop type classification (4 papers).

It is remarkable that all papers, except from (Demmers T. G., et al., 2010), (Demmers T. G., Cao, Parsons, Gauss, \& Wathes, 2012) and (Chen, Lin, Zhao, Wang, \& Gu, 2014), were published during or after 2015 , indicating how recent and modern this technique is, in the domain of agriculture. More precisely, from the remaining 37 papers, 15 papers have been published in 2017, 15 in 2016 and 7 in 2015.

The large majority of the papers deal with image classification and identification of areas of interest, including detection of obstacles (e.g. (Steen, Christiansen, Karstoft, \& Jørgensen, 2016), (Christiansen, Nielsen, Steen, Jørgensen, \& Karstoft, 2016)) and fruit counting (e.g. (Rahnemoonfar \& Sheppard, 2017), (Sa, et al., 2016)). Some papers focus on predicting future parameters, such as corn yield (Kuwata \& Shibasaki, 2015) soil moisture content at the field (Song, et al., 2016) and weather conditions (Sehgal, et al., 2017).

From another perspective, most papers (20) target crops, while few works consider issues such as weed detection (8 papers), land cover (4 papers), research on soil (2 papers), livestock agriculture (3 papers), obstacle detection (3 papers) and weather prediction (1 paper).

\subsection{Data Sources}

Observing the sources of data used to train the DL model at every paper, large datasets of images are mainly used, containing thousands of images in some cases, either real ones 
(e.g. (Mohanty, Hughes, \& Salathé, 2016), (Reyes, Caicedo, \& Camargo, 2015),

(Dyrmann, Karstoft, \& Midtiby, 2016 )), or synthetic produced by the authors

(Rahnemoonfar \& Sheppard, 2017), (Dyrmann, Mortensen, Midtiby, \& Jørgensen, 2016).

Some datasets originate from well-known and publicly-available datasets such as

PlantVillage, LifeCLEF, MalayaKew, UC Merced and Flavia (see Appendix III), while others constitute sets of real images collected by the authors for their research needs (e.g. (Sladojevic, Arsenovic, Anderla, Culibrk, \& Stefanovic, 2016), (Bargoti \& Underwood, 2016), (Xinshao \& Cheng, 2015), (Sørensen, Rasmussen, Nielsen, \& Jørgensen, 2017)). Papers dealing with land cover, crop type classification and yield estimation, as well as some papers related to weed detection employ a smaller number of images (e.g. tens of images), produced by UAV (Lu, et al., 2017), (Rebetez, J., et al., 2016), (Milioto, Lottes, \& Stachniss, 2017), airborne (Chen, Lin, Zhao, Wang, \& Gu, 2014), (Luus, Salmon, van den Bergh, \& Maharaj, 2015) or satellite-based remote sensing (Kussul, Lavreniuk, Skakun, \& Shelestov, 2017), (Minh, et al., 2017), (lenco, Gaetano, Dupaquier, \& Maurel, 2017), (Rußwurm \& Körner, 2017). A particular paper investigating segmentation of root and soil uses images from X-ray tomography (Douarre, Schielein, Frindel, Gerth, \& Rousseau, 2016). Moreover, some papers use text data, collected either from repositories (Kuwata \& Shibasaki, 2015), (Sehgal, et al., 2017) or field sensors (Song, et al., 2016), (Demmers T. G., et al., 2010), (Demmers T. G., Cao, Parsons, Gauss, \& Wathes, 2012). In general, the more complicated the problem to be solved, the more data is required. For example, problems involving large number of classes to identify (Mohanty, Hughes, \& Salathé, 2016), (Reyes, Caicedo, \& Camargo, 2015), (Xinshao \& Cheng, 2015) and/or small Variation among the classes (Luus, Salmon, van den Bergh, \& Maharaj, 2015), (Rußwurm \& Körner, 2017), (Yalcin, 2017 ), (Namin, Esmaeilzadeh, Najafi, Brown, \& Borevitz, 2017), (Xinshao \& Cheng, 2015), require large number of input images to train their models. 


\subsection{Data Variation}

Variation between classes is necessary for the DL models to be able to differentiate features and characteristics, and perform accurate classifications ${ }^{3}$. Hence, accuracy is positively correlated with variation among classes. Nineteen papers (47\%) revealed some aspects of poor data variation. Luus et al. (Luus, Salmon, van den Bergh, \& Maharaj, 2015) observed high relevance between some land cover classes (i.e. medium density and dense residential, buildings and storage tanks) while lenko et al. (lenco, Gaetano, Dupaquier, \& Maurel, 2017) found that tree crops, summer crops and truck farming were classes highly mixed. A confusion between maize and soybeans was evident in (Kussul, Lavreniuk, Skakun, \& Shelestov, 2017) and variation was low in botanically related crops, such as meadow, fallow, triticale, wheat, and rye (Rußwurm \& Körner, 2017). Moreover, some particular views of the plants (i.e. flowers and leaf scans) offer different classification accuracy than branches, stems and photos of the entire plant. A serious issue in plant phenology recognition is the fact that appearances change very gradually and it is challenging to distinguish images falling into the growing durations that are in the middle of two successive stages (Yalcin, 2017 ), (Namin, Esmaeilzadeh, Najafi, Brown, \& Borevitz, 2017). A similar issue appears when assessing the quality of vegetative development (Minh, et al., 2017). Furthermore, in the challenging problem of fruit counting, the models suffer from high occlusion, depth variation, and uncontrolled illumination, including high color similarity between fruit/foliage (Chen, et al., 2017), (Bargoti \& Underwood, 2016). Finally, identification of weeds faces issues with respect to lighting, resolution, and soil type, and small variation between weeds and crops in shape, texture, color and position (i.e. overlapping) (Dyrmann, Karstoft, \& Midtiby, 2016 ), (Xinshao \& Cheng, 2015), (Dyrmann, Jørgensen, \& Midtiby, 2017). In the large majority of the papers mentioned above (except from (Minh, et al., 2017)), this low variation has affected classification

\footnotetext{
${ }^{3}$ Classification accuracy is defined in Section 4.7 and Table 1.
} 
accuracy significantly, i.e. more than $5 \%$.

\subsection{Data Pre-Processing}

The large majority of related work (36 papers, $90 \%$ ) involved some image pre-processing steps, before the image or particular characteristics/features/statistics of the image were fed as an input to the DL model. The most common pre-processing procedure was image resize (16 papers), in most cases to a smaller size, in order to adapt to the requirements of the DL model. Sizes of $256 \times 256,128 \times 128,96 \times 96$ and $60 \times 60$ pixels were common. Image segmentation was also a popular practice (12 papers), either to increase the size of the dataset (lenco, Gaetano, Dupaquier, \& Maurel, 2017), (Rebetez, J., et al., 2016), (Yalcin, 2017 ) or to facilitate the learning process by highlighting regions of interest (Sladojevic, Arsenovic, Anderla, Culibrk, \& Stefanovic, 2016), (Mohanty, Hughes, \& Salathé, 2016), (Grinblat, Uzal, Larese, \& Granitto, 2016), (Sa, et al., 2016), (Dyrmann, Karstoft, \& Midtiby, 2016 ), (Potena, Nardi, \& Pretto, 2016) or to enable easier data annotation by experts and volunteers (Chen, et al., 2017), (Bargoti \& Underwood, 2016). Background removal (Mohanty, Hughes, \& Salathé, 2016), (McCool, Perez, \& Upcroft, 2017), (Milioto, Lottes, \& Stachniss, 2017), foreground pixel extraction (Lee, Chan, Wilkin, \& Remagnino, 2015) or non-green pixels removal based on NDVI masks (Dyrmann, Karstoft, \& Midtiby, 2016 ), (Potena, Nardi, \& Pretto, 2016) were also performed to reduce the datasets' overall noise. Other operations involved the creation of bounding boxes (Chen, et al., 2017), (Sa, et al., 2016), (McCool, Perez, \& Upcroft, 2017), (Milioto, Lottes, \& Stachniss, 2017) to facilitate detection of weeds or counting of fruits. Some datasets were converted to grayscale (Santoni, Sensuse, Arymurthy, \& Fanany, 2015), (Amara, Bouaziz, \& Algergawy, 2017) or to the HSV color model (Luus, Salmon, van den Bergh, \& Maharaj, 2015), (Lee, Chan, Wilkin, \& Remagnino, 2015).

Furthermore, some papers used features extracted from the images as input to their models, such as shape and statistical features (Hall, McCool, Dayoub, Sunderhauf, \& 
Upcroft, 2015), histograms (Hall, McCool, Dayoub, Sunderhauf, \& Upcroft, 2015), (Xinshao \& Cheng, 2015), (Rebetez, J., et al., 2016), Principal Component Analysis (PCA) filters (Xinshao \& Cheng, 2015), Wavelet transformations (Kuwata \& Shibasaki, 2015) and Gray Level Co-occurrence Matrix (GLCM) features (Santoni, Sensuse, Arymurthy, \& Fanany, 2015). Satellite or aerial images involved a combination of pre-processing steps such as orthorectification (Lu, et al., 2017), (Minh, et al., 2017) calibration and terrain correction (Kussul, Lavreniuk, Skakun, \& Shelestov, 2017), (Minh, et al., 2017) and atmospheric correction (Rußwurm \& Körner, 2017).

\subsection{Data Augmentation}

It is worth-mentioning that some of the related work under study (15 papers, 37\%) employed data augmentation techniques (Krizhevsky, Sutskever, \& Hinton, 2012), to enlarge artificially their number of training images. This helps to improve the overall learning procedure and performance, and for generalization purposes, by means of feeding the model with varied data. This augmentation process is important for papers that possess only small datasets to train their DL models, such as (Bargoti \& Underwood, 2016), (Sladojevic, Arsenovic, Anderla, Culibrk, \& Stefanovic, 2016), (Sørensen, Rasmussen, Nielsen, \& Jørgensen, 2017), (Mortensen, Dyrmann, Karstoft, Jørgensen, \& Gislum, 2016), (Namin, Esmaeilzadeh, Najafi, Brown, \& Borevitz, 2017) and (Chen, et al., 2017). This process was especially important in papers where the authors trained their models using synthetic images and tested them on real ones (Rahnemoonfar \& Sheppard, 2017) and (Dyrmann, Mortensen, Midtiby, \& Jørgensen, 2016). In this case, data augmentation allowed their models to generalize and be able to adapt to the real-world problems more easily.

Transformations are label-preserving, and included rotations (12 papers), dataset partitioning/cropping (3 papers), scaling (3 papers), transposing (Sørensen, Rasmussen, Nielsen, \& Jørgensen, 2017), mirroring (Dyrmann, Karstoft, \& Midtiby, 2016 ), translations 
and perspective transform (Sladojevic, Arsenovic, Anderla, Culibrk, \& Stefanovic, 2016), adaptations of objects' intensity in an object detection problem (Steen, Christiansen, Karstoft, \& Jørgensen, 2016) and a PCA augmentation technique (Bargoti \& Underwood, 2016).

Papers involving simulated data performed additional augmentation techniques such as varying the HSV channels and adding random shadows (Dyrmann, Mortensen, Midtiby, \& Jørgensen, 2016) or adding simulated roots to soil images (Douarre, Schielein, Frindel, Gerth, \& Rousseau, 2016).

\subsection{Technical Details}

From a technical side, almost half of the research works (17 papers, $42 \%$ ) employed popular CNN architectures such as AlexNet, VGG16 and Inception-ResNet. From the rest, 14 papers developed their own CNN models, 2 papers adopted a first-order Differential Recurrent Neural Networks (DRNN) model, 5 papers preferred to use a Long Short-Term Memory (LSTM) model (Gers, Schmidhuber, \& Cummins, 2000), one paper used deep belief networks (DBN) and one paper employed a hybrid of PCA with auto-encoders (AE). Some of the CNN approaches combined their model with a classifier at the output layer, such as logistic regression (Chen, Lin, Zhao, Wang, \& Gu, 2014), Scalable Vector Machines (SVM) (Douarre, Schielein, Frindel, Gerth, \& Rousseau, 2016), linear regression (Chen, et al., 2017), Large Margin Classifiers (LCM) (Xinshao \& Cheng, 2015) and macroscopic cellular automata (Song, et al., 2016).

Regarding the frameworks used, all the works that employed some well-known CNN architecture had also used a DL framework, with Caffe being the most popular (13 papers, 32\%), followed by Tensor Flow (2 papers) and deeplearning4j (1 paper). Ten research works developed their own software, while some authors decided to build their own models on top of Caffe (5 papers), Keras/Theano (5 papers), Keras/TensorFlow (4 papers), Pylearn2 (1 paper), MatConvNet (1 paper) and Deep Learning Matlab Toolbox (1 
paper). A possible reason for the wide use of Caffe is that it incorporates various CNN frameworks and datasets, which can be used then easily and automatically by its users. Most of the studies divided their dataset between training and testing/verification data using a ratio of $80-20$ or $90-10$ respectively. In addition, various learning rates have been recorded, from 0.001 (Amara, Bouaziz, \& Algergawy, 2017) and 0.005 (Mohanty, Hughes, \& Salathé, 2016) up to 0.01 (Grinblat, Uzal, Larese, \& Granitto, 2016). Learning rate is about how quickly a network learns. Higher values help avoid the solver being stuck in local minima, which can reduce performance significantly. A general approach used by many of the evaluated papers is to start out with a high learning rate and lower it as the training goes on. We note that learning rate is very dependent on the network architecture. Moreover, most of the research works that incorporated popular DL architectures took advantage of transfer learning (Pan \& Yang, 2010), which concerns leveraging the already existing knowledge of some related task or domain in order to increase the learning efficiency of the problem under study by fine-tuning pre-trained models. As sometimes it is not possible to train a network from scratch due to having a small training data set or having a complex multi-task network, it is required that the network be at least partially initialized with weights from another pre-trained model. A common transfer learning technique is the use of pre-trained CNN, which are CNN models that have been already trained on some relevant dataset with possibly different number of classes. These models are then adapted to the particular challenge and dataset. This method was followed (among others) in (Lu, et al., 2017), (Douarre, Schielein, Frindel, Gerth, \& Rousseau, 2016), (Reyes, Caicedo, \& Camargo, 2015), (Bargoti \& Underwood, 2016), (Steen, Christiansen, Karstoft, \& Jørgensen, 2016), (Lee, Chan, Wilkin, \& Remagnino, 2015), (Sa, et al., 2016), (Mohanty, Hughes, \& Salathé, 2016), (Christiansen, Nielsen, Steen, Jørgensen, \& Karstoft, 2016), (Sørensen, Rasmussen, Nielsen, \& Jørgensen, 2017), for the VGG16, DenseNet, AlexNet and GoogleNet architectures. 


\subsection{Outputs}

Finally, concerning the 31 papers that involved classification, the classes as used by the authors ranged from 2 (Lu, et al., 2017), (Pound, M. P., et al., 2016), (Douarre, Schielein, Frindel, Gerth, \& Rousseau, 2016), (Milioto, Lottes, \& Stachniss, 2017) up to 1,000 (Reyes, Caicedo, \& Camargo, 2015). A large number of classes was observed in (Luus, Salmon, van den Bergh, \& Maharaj, 2015) (21 land-use classes), (Rebetez, J., et al., 2016) (22 different crops plus soil), (Lee, Chan, Wilkin, \& Remagnino, 2015) (44 plant species) and (Xinshao \& Cheng, 2015) (91 classes of common weeds found in agricultural fields). In these papers, the number of outputs of the model was equal to the number of classes respectively. Each output was a different probability for the input image, segment, blob or pixel to belong to each class, and then the model picked the highest probability as its predicted class.

From the rest 9 papers, 2 performed predictions of fruits counted (scalar value as output) (Rahnemoonfar \& Sheppard, 2017), (Chen, et al., 2017), 2 identified regions of fruits in the image (multiple bounding boxes) (Bargoti \& Underwood, 2016), (Sa, et al., 2016), 2 predicted animal growth (scalar value) (Demmers T. G., et al., 2010), (Demmers T. G., Cao, Parsons, Gauss, \& Wathes, 2012), one predicted weather conditions (scalar value) (Sehgal, et al., 2017), one crop yield index (scalar value) (Kuwata \& Shibasaki, 2015) and one paper predicted percentage of soil moisture content (scalar value) (Song, et al., 2016).

\subsection{Performance Metrics}

Regarding methods used to evaluate performance, various metrics have been employed by the authors, each being specific to the model used at each study. Table 1 lists these metrics, together with their definition/description, and the symbol we use to refer to them in this survey. In some papers where the authors referred to accuracy without specifying its definition, we assumed they referred to classification accuracy (CA, first metric listed in Table 1). From this point onwards, we refer to "DL performance" as its score in some 
Table 1: Performance metrics used in related work under study.

\begin{tabular}{|c|c|c|c|}
\hline No. & $\begin{array}{l}\text { Performance } \\
\text { Metric }\end{array}$ & $\begin{array}{l}\text { Symbol } \\
\text { Used }\end{array}$ & Description \\
\hline 1. & $\begin{array}{l}\text { Classification } \\
\text { Accuracy }\end{array}$ & CA & $\begin{array}{l}\text { The percentage of correct predictions where the top class (the one } \\
\text { having the highest probability), as indicated by the DL model, is the } \\
\text { same as the target label as annotated beforehand by the authors. For } \\
\text { multi-class classification problems, CA is averaged among all the } \\
\text { classes. CA is mentioned as Rank-1 identification rate in (Hall, } \\
\text { McCool, Dayoub, Sunderhauf, \& Upcroft, 2015). }\end{array}$ \\
\hline 2. & Precision & $P$ & $\begin{array}{l}\text { The fraction of true positives (TP, correct predictions) from the total } \\
\text { amount of relevant results, i.e. the sum of TP and false positives (FP). } \\
\text { For multi-class classification problems, } P \text { is averaged among the } \\
\text { classes. } P=T P /(T P+F P)\end{array}$ \\
\hline 3. & Recall & $\mathrm{R}$ & $\begin{array}{l}\text { The fraction of TP from the total amount of TP and false negatives } \\
\text { (FN). For multi-class classification problems, } R \text { gets averaged among } \\
\text { all the classes. } R=T P /(T P+F N)\end{array}$ \\
\hline 4. & F1 score & F1 & $\begin{array}{l}\text { The harmonic mean of precision and recall. For multi-class } \\
\text { classification problems, F1 gets averaged among all the classes. It is } \\
\text { mentioned as F-measure in (Minh, et al., 2017). } \\
F 1=2 *\left(T P^{*} F P\right) /(T P+F P)\end{array}$ \\
\hline 5. & LifeCLEF metric & LC & $\begin{array}{l}\text { A score }{ }^{4} \text { related to the rank of the correct species in the list of retrieved } \\
\text { species }\end{array}$ \\
\hline 6. & Quality Measure & QM & $\begin{array}{l}\text { Obtained by multiplying sensitivity (proportion of pixels that were } \\
\text { detected correctly) and specificity (which proportion of detected pixels } \\
\text { are truly correct). QM=TP2 / ((TP+FP)(TP+FN)) }\end{array}$ \\
\hline 7. & Mean Square Error & MSE & $\begin{array}{l}\text { Mean of the square of the errors between predicted and observed } \\
\text { values. }\end{array}$ \\
\hline 8. & $\begin{array}{l}\text { Root Mean Square } \\
\text { Error }\end{array}$ & RMSE & $\begin{array}{l}\text { Standard deviation of the differences between predicted values and } \\
\text { observed values. A normalized RMSE (N-RMSE) has been used in } \\
\text { (Sehgal, et al., 2017). }\end{array}$ \\
\hline 9. & $\begin{array}{l}\text { Mean Relative } \\
\text { Error }\end{array}$ & MRE & $\begin{array}{l}\text { The mean error between predicted and observed values, in } \\
\text { percentage. }\end{array}$ \\
\hline 10. & $\begin{array}{l}\text { Ratio of total fruits } \\
\text { counted }\end{array}$ & RFC & $\begin{array}{l}\text { Ratio of the predicted count of fruits by the model, with the actual } \\
\text { count. The actual count was attained by taking the average count of } \\
\text { individuals (i.e. experts or volunteers) observing the images } \\
\text { independently. }\end{array}$ \\
\hline 11. & L2 error & L2 & $\begin{array}{l}\text { Root of the squares of the sums of the differences between predicted } \\
\text { counts of fruits by the model and the actual counts. }\end{array}$ \\
\hline 12. & $\begin{array}{l}\text { Intersection over } \\
\text { Union }\end{array}$ & loU & $\begin{array}{l}\text { A metric that evaluates predicted bounding boxes, by dividing the area } \\
\text { of overlap between the predicted and the ground truth boxes, by the } \\
\text { area of their union. An average (Dyrmann, Mortensen, Midtiby, \& } \\
\text { Jørgensen, 2016) or frequency weighted (Mortensen, Dyrmann, } \\
\text { Karstoft, Jørgensen, \& Gislum, 2016) loU can be calculated. }\end{array}$ \\
\hline 13. & CA-IoU, F1-IoU, & CA-IoU & These are the same CA, F1, P and R metrics as defined above, \\
\hline
\end{tabular}

\footnotetext{
${ }^{4}$ LifeCLEF 2015 Challenge. http://www.imageclef.org/lifeclef/2015/plant
} 


\begin{tabular}{|l|l|l|}
\hline P-loU or R-IoU & $\begin{array}{c}\text { F1-loU } \\
\text { P-loU } \\
\text { R-loU }\end{array}$ & $\begin{array}{l}\text { combined with loU in order to consider true/false positives/negatives. } \\
\text { Used in problems involving bounding boxes. This is done by putting a } \\
\text { minimum threshold on loU, i.e. any value above this threshold would } \\
\text { be considered as positive by the metric (and the model involved). } \\
\text { Thresholds of 20\% (Bargoti \& Underwood, 2016), 40\% (Sa, et al., } \\
\text { 2016) and 50\% (Steen, Christiansen, Karstoft, \& Jørgensen, 2016), } \\
\text { (Christiansen, Nielsen, Steen, Jørgensen, \& Karstoft, 2016), } \\
\text { (Dyrmann, Jørgensen, \& Midtiby, 2017) have been observed }\end{array}$ \\
\hline
\end{tabular}

CA was the most popular metric used (24 papers, $60 \%$ ), followed by F1 (10 papers, $25 \%$ ). Some papers included RMSE (4 papers), loU (3 papers), RFC (Chen, et al., 2017), (Rahnemoonfar \& Sheppard, 2017) or others. Some works used a combination of metrics to evaluate their efforts. We note that some papers employing CA, F1, P or R, used loU in order to consider a model's prediction (Bargoti \& Underwood, 2016), (Sa, et al., 2016), (Steen, Christiansen, Karstoft, \& Jørgensen, 2016), (Christiansen, Nielsen, Steen, Jørgensen, \& Karstoft, 2016), (Dyrmann, Jørgensen, \& Midtiby, 2017). In these cases, a minimum threshold was put on loU, and any value above this threshold would be considered as positive by the model.

We note that in some cases, a trade-off can exist between metrics. For example, in a weed detection problem (Milioto, Lottes, \& Stachniss, 2017), it might be desirable to have a high $\mathrm{R}$ to eliminate most weeds, but not eliminating crops is of a critical importance, hence a lower P might be acceptable.

\subsection{Overall Performance}

We note that it is difficult if not impossible to compare between papers, as different metrics are employed for different tasks, considering different models, datasets and parameters. Hence, the reader should consider our comments in this section with some caution. In 19 out of the 24 papers that involved CA as a metric, accuracy was high (i.e. above $90 \%$ ), indicating good performance. The highest CA has been observed in the works of (Hall, McCool, Dayoub, Sunderhauf, \& Upcroft, 2015), (Pound, M. P., et al., 2016), (Chen,

\footnotetext{
${ }^{5}$ In Appendix II, where we list the values of the metrics used at each paper, we denote CA-loU(x), $F 1-\operatorname{loU}(\mathrm{x})$, $\mathrm{P}-\operatorname{loU}(\mathrm{x})$ or $\mathrm{R}-\mathrm{loU}(\mathrm{x})$, where $\mathrm{x}$ is the threshold (in percentage), over which results are considered as positive by the DL model employed.
} 
Lin, Zhao, Wang, \& Gu, 2014), (Lee, Chan, Wilkin, \& Remagnino, 2015), (Minh, et al., 2017), (Potena, Nardi, \& Pretto, 2016) and (Steen, Christiansen, Karstoft, \& Jørgensen, 2016), with values of $98 \%$ or more, constituting remarkable results. From the 10 papers using F1 as metric, 5 had values higher than 0.90 with the highest F1 observed in (Mohanty, Hughes, \& Salathé, 2016) and (Minh, et al., 2017) with values higher than 0.99. The works of (Dyrmann, Karstoft, \& Midtiby, 2016 ), (Rußwurm \& Körner, 2017), (lenco, Gaetano, Dupaquier, \& Maurel, 2017), (Mortensen, Dyrmann, Karstoft, Jørgensen, \& Gislum, 2016), (Rebetez, J., et al., 2016), (Christiansen, Nielsen, Steen, Jørgensen, \& Karstoft, 2016) and (Yalcin, 2017 ) were among the ones with the lowest CA (i.e. 73-79\%) and/or F1 scores (i.e. 0.558 - 0.746), however state of the art work in these particular problems has shown lower CA (i.e. SVM, RF, Naïve- Bayes classifier). Particularly in (Rußwurm \& Körner, 2017), the three-unit LSTM model employed provided 16.3\% better CA than a CNN, which belongs to the family of DL. Besides, the above can be considered as "harder" problems, because of the use of satellite data (lenco, Gaetano, Dupaquier, \& Maurel, 2017), (Rußwurm \& Körner, 2017) large number of classes (Dyrmann, Karstoft, \& Midtiby, 2016 ), (Rußwurm \& Körner, 2017), (Rebetez, J., et al., 2016), small training datasets (Mortensen, Dyrmann, Karstoft, Jørgensen, \& Gislum, 2016), (Christiansen, Nielsen, Steen, Jørgensen, \& Karstoft, 2016) or very low variation among the classes (Yalcin, 2017 ), (Dyrmann, Karstoft, \& Midtiby, 2016 ), (Rebetez, J., et al., 2016).

\subsection{Generalizations on Different Datasets}

It is important to examine whether the authors had tested their implementations on the same dataset (e.g. by dividing the dataset into training and testing/validation sets) or used different datasets to test their solution. From the 40 papers, only 8 (20\%) used different datasets for testing than the one for training. From these, 2 approaches trained their models by using simulated data and tested on real data (Dyrmann, Mortensen, Midtiby, \& Jørgensen, 2016), (Rahnemoonfar \& Sheppard, 2017) and 2 papers tested their models 
on a dataset produced 2-4 weeks after, with a more advanced growth stage of plants and weeds (Milioto, Lottes, \& Stachniss, 2017), (Potena, Nardi, \& Pretto, 2016). Moreover, 3 papers used different fields for testing than the ones used for training (McCool, Perez, \& Upcroft, 2017), with a severe degree of occlusion compared to the other training field (Dyrmann, Jørgensen, \& Midtiby, 2017), or containing other obstacles such as people and animals (Steen, Christiansen, Karstoft, \& Jørgensen, 2016). Sa et al. (Sa, et al., 2016) used a different dataset to evaluate whether the model can generalize on different fruits. From the other 32 papers, different trees were used in training and testing in (Chen, et al., 2017), while different rooms for pigs (Demmers T. G., Cao, Parsons, Gauss, \& Wathes, 2012) and chicken (Demmers T. G., et al., 2010) were considered. Moreover, Hall et al. applied condition variations in testing (i.e. translations, scaling, rotations, shading and occlusions) (Hall, McCool, Dayoub, Sunderhauf, \& Upcroft, 2015) while scaling for a certain range translation distance and rotation angle was performed on the testing dataset in (Xinshao \& Cheng, 2015). The rest 27 papers did not perform any changes between the training/testing datasets, a fact that lowers the overall confidence for the results presented. Finally, it is interesting to observe how these generalizations affected the performance of the models, at least in cases where both data from same and different datasets were used in testing. In (Sa, et al., 2016), F1-loU(40) was higher for the detection of apples (0.938), strawberry (0.948), avocado (0.932) and mango (0.942), than in the default case of sweet pepper (0.838). In (Rahnemoonfar \& Sheppard, 2017), RFC was $2 \%$ less in the real images than in the synthetic ones. In (Potena, Nardi, \& Pretto, 2016), CA was $37.6 \%$ less at the dataset involving plants of 4-weeks more advanced growth. According to the authors, the model was trained based on plants that were in their first growth stage, thus without their complete morphological features, which were included in the testing dataset. Moreover, in (Milioto, Lottes, \& Stachniss, 2017) P was 2\% higher at the 2-weeks more advanced growth dataset, with 9\% lower R. 
Hence, in the first case there was improvement in performance (Sa, et al., 2016), and in the last three cases a reduction, slight one in (Rahnemoonfar \& Sheppard, 2017) and (Milioto, Lottes, \& Stachniss, 2017) but considerable in (Potena, Nardi, \& Pretto, 2016). From the other papers using different testing datasets, as mentioned above, high percentages of CA (94-97.3\%), P-IoU (86.6\%) and low values of MRE (1.8 -10\%) have been reported. These show that the DL models were able to generalize well to different datasets. However, without more comparisons, this is only a speculation that can be figured out of the small number of observations available.

\subsection{Performance Comparison with Other Approaches}

A critical aspect of this survey is to examine how DL performs in relation to other existing techniques. The $14^{\text {th }}$ column of Appendix II presents whether the authors of related work compared their DL-based approach with other techniques used for solving their problem under study. We focus only on comparisons between techniques used for the same dataset at the same research paper, with the same metric.

In almost all cases, the DL models outperform other approaches implemented for comparison purposes. CNN show 1-8\% higher CA in comparison to SVM (Chen, Lin, Zhao, Wang, \& Gu, 2014), (Lee, Chan, Wilkin, \& Remagnino, 2015), (Grinblat, Uzal, Larese, \& Granitto, 2016), (Pound, M. P., et al., 2016), 41\% improvement of CA when compared to ANN (Lee, Chan, Wilkin, \& Remagnino, 2015) and 3-8\% higher CA when compared to RF (Kussul, Lavreniuk, Skakun, \& Shelestov, 2017), (Minh, et al., 2017), (McCool, Perez, \& Upcroft, 2017), (Potena, Nardi, \& Pretto, 2016), (Hall, McCool, Dayoub, Sunderhauf, \& Upcroft, 2015). CNN also seem to be superior than unsupervised feature learning with 3-11\% higher CA (Luus, Salmon, van den Bergh, \& Maharaj, 2015), 2-44\% improved CA in relation to local shape and color features (Dyrmann, Karstoft, \& Midtiby, 2016 ), (Sørensen, Rasmussen, Nielsen, \& Jørgensen, 2017), and 2\% better CA (Kussul, Lavreniuk, Skakun, \& Shelestov, 2017) or 18\% less RMSE (Song, et al., 2016) compared 
to multilayer perceptrons. CNN had also superior performance than Penalized

Discriminant Analysis (Grinblat, Uzal, Larese, \& Granitto, 2016), SVM Regression (Kuwata \& Shibasaki, 2015), area-based techniques (Rahnemoonfar \& Sheppard, 2017), texturebased regression models (Chen, et al., 2017), LMC classifiers (Xinshao \& Cheng, 2015), Gaussian Mixture Models (Santoni, Sensuse, Arymurthy, \& Fanany, 2015) and NaïveBayes classifiers (Yalcin, 2017 ).

In cases where Recurrent Neural Networks (RNN) (Mandic \& Chambers, 2001) architectures were employed, the LSTM model had 1\% higher CA than RF and SVM in (lenco, Gaetano, Dupaquier, \& Maurel, 2017), 44\% improved CA than SVM in (Rußwurm \& Körner, 2017) and 7-9\% better CA than RF and SVM in (Minh, et al., 2017).

In only one case, DL showed worse performance against another technique, and this was when a CNN was compared to an approach involving local descriptors to represent images together with KNN as the classification strategy (20\% worse LC) (Reyes, Caicedo, \& Camargo, 2015).

\section{Discussion}

Our analysis has shown that DL offers superior performance in the vast majority of related work. When comparing the performance of DL-based approaches with other techniques at each paper, it is of paramount importance to adhere to the same experimental conditions (i.e. datasets and performance metrics). From the related work under study, 28 out of the 40 papers $(70 \%)$ performed direct, valid and correct comparisons among the DL-based approach employed and other state-of-art techniques used to solve the particular problem tackled at each paper. Due to the fact that each paper involved different datasets, preprocessing techniques, metrics, models and parameters, it is difficult if not impossible to generalize and perform comparisons between papers. Thus, our comparisons have been strictly limited among the techniques used at each paper. Thus, based on these 
constraints, we have observed that DL has outperformed traditional approaches used such as SVM, RF, ANN, LMC classifiers and others. It seems that the automatic feature extraction performed by DL models is more effective than the feature extraction process through traditional approaches such as Scale Invariant Feature Transform (SIFT), GLCM, histograms, area-based techniques (ABT), statistics-, texture-, color- and shape-based algorithms, conditional random fields to model color and visual texture features, local decorrelated channel features and other manual feature extraction techniques. This is reinforced by the combined CNN+LSTM model employed in (Namin, Esmaeilzadeh, Najafi, Brown, \& Borevitz, 2017), which outperformed a LSTM model which used hand crafted feature descriptors as inputs by $25 \%$ higher CA. Interesting attempts to combine handcrafted features and CNN-based features were performed in (Hall, McCool, Dayoub, Sunderhauf, \& Upcroft, 2015) and (Rebetez, J., et al., 2016).

Although DL has been associated with computer vision and image analysis (which is also the general case in this survey), we have observed 5 related works where DL-based models have been trained based on field sensory data (Kuwata \& Shibasaki, 2015), (Sehgal, et al., 2017) and a combination of static and dynamic environmental variables (Song, et al., 2016), (Demmers T. G., et al., 2010), (Demmers T. G., Cao, Parsons, Gauss, \& Wathes, 2012). These papers indicate the potential of DL to be applied in a wide variety of agricultural problems, not only those involving images.

Examining agricultural areas where DL techniques have been applied, leaf classification, leaf and plant disease detection, plant recognition and fruit counting have some papers which present very good performance (i.e. CA $>95 \%, \mathrm{~F} 1>0.92$ or RFC $>0.9$ ). This is probably because of the availability of datasets in these domains, as well as the distinct characteristics of (sick) leaves/plants and fruits in the image. On the other hand, some papers in land cover classification, crop type classification, plant phenology recognition and weed detection showed average performance (i.e. CA $<87 \%$ or $\mathrm{F} 1<0.8$ ). This could 
be due to leaf occlusion in weed detection, use of noise-prone satellite imagery in land cover problems, crops with low variation and botanical relationship or the fact that appearances change very gradually while plants grow in phenology recognition efforts. Without underestimating the quality of any of the surveyed papers, we highlight some that claim high performance $(\mathrm{CA}>91 \%, \mathrm{~F} 1-\operatorname{loU}(20)>0.90$ or $\mathrm{RFC}>0.91)$, considering the complexity of the problem in terms of its definition or the large number of classes involved (more than 21 classes). These papers are the following: (Mohanty, Hughes, \& Salathé, 2016), (Luus, Salmon, van den Bergh, \& Maharaj, 2015), (Lee, Chan, Wilkin, \& Remagnino, 2015), (Rahnemoonfar \& Sheppard, 2017), (Chen, et al., 2017), (Bargoti \& Underwood, 2016), (Xinshao \& Cheng, 2015) and (Hall, McCool, Dayoub, Sunderhauf, \& Upcroft, 2015). We also highlight papers that trained their models on simulated data, and tested them on real data, which are (Dyrmann, Mortensen, Midtiby, \& Jørgensen, 2016), (Rahnemoonfar \& Sheppard, 2017), and (Douarre, Schielein, Frindel, Gerth, \& Rousseau, 2016). These works constitute important efforts in the DL community, as they attempt to solve the problem of inexistent or not large enough datasets in various problems.

Finally, as discussed in Section 4.10, most authors used the same datasets for training and testing their implementation, a fact that lowers the confidence in the overall findings, although there have been indications that the models seem to generalize well, with only small reductions in performance.

\subsection{Advanced Deep Learning Applications}

Although the majority of papers used typical CNN architectures to perform classification (23 papers, 57\%), some authors experimented with more advanced models in order to solve more complex problems, such as crop type classification from UAV imagery (CNN + HistNN using RGB histograms) (Rebetez, J., et al., 2016), estimating number of tomato fruits (Modified Inception-ResNet CNN) (Rahnemoonfar \& Sheppard, 2017) and estimating number of orange or apple fruits (CNN adapted for blob detection and counting + Linear 
Regression) (Chen, et al., 2017). Particularly interesting were the approaches employing the Faster Region-based CNN + VGG16 model (Bargoti \& Underwood, 2016), (Sa, et al., 2016), in order not only to count fruits and vegetables, but also to locate their placement in the image by means of bounding boxes. Similarly, the work in (Dyrmann, Jørgensen, \& Midtiby, 2017) used the DetectNet CNN to detect bounding boxes of weed instances in images of cereal fields. These approaches (Faster Region-based CNN, DetectNet CNN) constitute a very promising research direction, since the task of identifying the bounding box of fruits/vegetables/weeds in an image has numerous real-life applications and could solve various agricultural problems

Moreover, considering not only space but also time series, some authors employed RNNbased models in land cover classification (one-unit LSTM model + SVM) (lenco, Gaetano, Dupaquier, \& Maurel, 2017), crop type classification (three-unit LSTM) (Rußwurm \& Körner, 2017), classification of different accessions of Arabidopsis thaliana based on successive top-view images (CNN+ LSTM) (Namin, Esmaeilzadeh, Najafi, Brown, \& Borevitz, 2017), mapping winter vegetation quality coverage (Five-unit LSTM, Gated Recurrent Unit) (Minh, et al., 2017), estimating the weight of pigs or chickens (DRNN) (Demmers T. G., et al., 2010), (Demmers T. G., Cao, Parsons, Gauss, \& Wathes, 2012) and for predicting weather based on previous year's conditions (LSTM) (Sehgal, et al., 2017). RNN-based models offer higher performance, as they can capture the time dimension, which is impossible to be exploited by simple CNN. RNN architectures tend to exhibit dynamic temporal behavior, being able to record long-short temporal dependencies, remembering and forgetting after some time or when needed (i.e. LSTM). Differences in performance between RNN and CNN are distinct in the related work under study, as shown in Table 2. This $16 \%$ improvement in CA could be attributed to the additional information provided by the time series. For example, in the crop type classification case (Rußwurm \& Körner, 2017), the authors mention, "crops change their 
spectral characteristics due to environmental influences and can thus not be monitored effectively with classical mono-temporal approaches. Performance of temporal models increases at the beginning of vegetation period". LSTM-based approaches work well also for low represented and difficult classes, as demonstrated in (lenco, Gaetano, Dupaquier, \& Maurel, 2017).

Table 2: Difference in Performance between CNN and RNN.

\begin{tabular}{|l|l|l|l|l|}
\hline No. & $\begin{array}{l}\text { Application in } \\
\text { Agriculture }\end{array}$ & $\begin{array}{l}\text { Performan } \\
\text { ce Metric }\end{array}$ & Difference in Performance & Reference \\
\hline 1. & $\begin{array}{l}\text { Crop type classification } \\
\text { considering time series }\end{array}$ & CA, F1 & $\begin{array}{l}\text { Three-unit LSTM: 76.2\% (CA), } \\
0.558 \text { (F1) } \\
\text { CNN: 59.9\% (CA), 0.236 (F1) }\end{array}$ & (Rußwurm \& Körner, 2017) \\
\hline 2. & $\begin{array}{l}\text { Classify the phenotyping } \\
\text { of Arabidopsis in four } \\
\text { accessions }\end{array}$ & CA & $\begin{array}{l}\text { CNN+ LSTM: 93\% } \\
\text { CNN: 76.8\% }\end{array}$ & $\begin{array}{l}\text { (Namin, Esmaeilzadeh, } \\
\text { Najafi, Brown, \& Borevitz, } \\
2017)\end{array}$ \\
\hline
\end{tabular}

Finally, the critical aspect of fast processing of DL models in order to be easily used in robots for real-time decision making (e.g. detection of weeds) was examined in (McCool, Perez, \& Upcroft, 2017), and it is worth-mentioning. The authors have showed that a lightweight implementation had only a small penalty in CA (3.90\%), being much faster (i.e. processing of 40.6 times more pixels per second). They proposed the idea of "teacher and student networks", where the teacher is the more heavy approach that helps the student (light implementation) to learn faster and better.

\subsection{Advantages of Deep Learning}

Except from improvements in performance of the classification/prediction problems in the surveyed works (see Sections 4.9 and 4.11), the advantage of DL in terms of reduced effort in feature engineering was demonstrated in many of the papers. Hand-engineered components require considerable time, an effort that takes place automatically in DL.

Besides, sometimes manual search for good feature extractors is not an easy and obvious task. For example, in the case of estimating crop yield (Kuwata \& Shibasaki, 2015), extracting manually features that significantly affected crop growth was not possible. This 
was also the case of estimating the soil moisture content (Song, et al., 2016).

Moreover, DL models seem to generalize well. For example, in the case of fruit counting, the model learned explicitly to count (Rahnemoonfar \& Sheppard, 2017). In the banana leaf classification problem (Amara, Bouaziz, \& Algergawy, 2017), the model was robust under challenging conditions such as illumination, complex background, different resolution, size and orientation of the images. Also in the fruits counting papers (Chen, et al., 2017), (Rahnemoonfar \& Sheppard, 2017), the models were robust to occlusion, variation, illumination and scale. The same detection frameworks could be used for a variety of circular fruits such as peaches, citrus, mangoes etc. As another example, a key feature of the DeepAnomaly model was the ability to detect unknown objects/anomalies and not just a set of predefined objects, exploiting the homogeneous characteristics of an agricultural field to detect distant, heavy occluded and unknown objects (Christiansen, Nielsen, Steen, Jørgensen, \& Karstoft, 2016). Moreover, in the 8 papers mentioned in Section 4.10 where different datasets were used for testing, the performance of the model was generally high, with only small reductions in performance in comparison with the performance when using the same dataset for training and testing.

Although DL takes longer time to train than other traditional approaches (e.g. SVM, RF), its testing time efficiency is quite fast. For example, in detecting obstacles and anomaly (Christiansen, Nielsen, Steen, Jørgensen, \& Karstoft, 2016), the model took much longer to train, but after it did, its testing time was less than the one of SVM and KNN. Besides, if we take into account the time needed to manually design filters and extract features, "the time used on annotating images and training the CNN becomes almost negligible" (Sørensen, Rasmussen, Nielsen, \& Jørgensen, 2017).

Another advantage of $\mathrm{DL}$ is the possibility to develop simulated datasets to train the model, which could be properly designed in order to solve real-world problems. For example, in the issue of detecting weeds and maize in fields (Dyrmann, Mortensen, 
Midtiby, \& Jørgensen, 2016), the authors overcame the plant foliage overlapping problem by simulating top-down images of overlapping plants on soil background. The trained network was then capable of distinguish weeds from maize even in overlapping conditions.

\subsection{Disadvantages and Limitations of Deep Learning}

A considerable drawback and barrier in the use of $D L$ is the need of large datasets, which would serve as the input during the training procedure. In spite of data augmentation techniques which augment some dataset with label-preserving transformations, in reality at least some hundreds of images are required, depending on the complexity of the problem under study (i.e. number of classes, precision required etc.). For example, the authors in (Mohanty, Hughes, \& Salathé, 2016) and (Sa, et al., 2016) commented that a more diverse set of training data was needed to improve CA. A big problem with many datasets is the low variation among the different classes (Yalcin, 2017 ), as discussed in Section 4.3, or the existence of noise, in the form of low resolution, inaccuracy of sensory equipment (Song, et al., 2016), crops' occlusions, plants overlapping and clustering, and others. As data annotation is a necessary operation in the large majority of cases, some tasks are more complex and there is a need for experts (who might be difficult to involve) in order to annotate input images. As mentioned in (Amara, Bouaziz, \& Algergawy, 2017), there is a limited availability of resources and expertise on banana pathology worldwide. In some cases, experts or volunteers are susceptible to errors during data labeling, especially when this is a challenging task e.g. fruit count (Chen, et al., 2017), (Bargoti \& Underwood, 2016) or to determine if images contain weeds or not (Sørensen, Rasmussen, Nielsen, \& Jørgensen, 2017), (Dyrmann, Jørgensen, \& Midtiby, 2017).

Another limitation is the fact that the DL models can learn some problem particularly well, even generalize in some aspects as mentioned in Section 5.2, but they cannot generalize beyond the "boundaries of the dataset's expressiveness". For example, classification of single leaves, facing up, on a homogeneous background is performed in (Mohanty, 
Hughes, \& Salathé, 2016). A real world application should be able to classify images of a disease as it presents itself directly on the plant. Many diseases do not present themselves on the upper side of leaves only. As another example, plant recognition in (Lee, Chan, Wilkin, \& Remagnino, 2015) was noticeably affected by environmental factors such as wrinkled surface and insect damages. The model for counting tomatoes in (Rahnemoonfar \& Sheppard, 2017) could count ripe and half-ripe fruits, however, "it failed to count green fruits because it was not trained for this purpose". If an object size in a testing image was significantly less than that of a training set, the model missed the detection in (Sa, et al., 2016). Difficulty in detecting heavily occluded and distant objects was observed in (Christiansen, Nielsen, Steen, Jørgensen, \& Karstoft, 2016). Occlusion was a serious issue also in (Hall, McCool, Dayoub, Sunderhauf, \& Upcroft, 2015). A general issue in computer vision, not only in $\mathrm{DL}$, is that data pre-processing is sometimes a necessary and time-consuming task, especially when satellite or aerial photos are involved, as we saw in Section 4.4. A problem with hyperspectral data is their high dimensionality and limited training samples (Chen, Lin, Zhao, Wang, \& Gu, 2014). Moreover, sometimes the existing datasets do not describe completely the problem they target (Song, et al., 2016). As an example, for estimating corn yield (Kuwata \& Shibasaki, 2015), it was necessary to consider also external factors other than the weather by inputting cultivation information such as fertilization and irrigation.

Finally, in the domain of agriculture, there do not exist many publicly available datasets for researchers to work with, and in many cases, researchers need to develop their own sets of images. This could require many hours or days of work.

\subsection{Future of Deep Learning in Agriculture}

Observing Appendix I, which lists various existing applications of computer vision in agriculture, we can see that only the problems of land cover classification, crop type estimation, crop phenology, weed detection and fruit grading have been approximated 
using DL. It is interesting to see how DL would behave also in other agricultural-related problems listed in Appendix I, such as seeds identification, soil and leaf nitrogen content, irrigation, plants' water stress detection, water erosion assessment, pest detection, herbicide use, identification of contaminants, diseases or defects on food, crop hail damage and greenhouse monitoring. Intuitively, since many of the aforementioned research areas employ data analysis techniques (see Appendix I) with similar concepts and comparable performance to DL (i.e. linear and logistic regression, SVM, KNN, Kmeans clustering, Wavelet-based filtering, Fourier transform) (Singh, Ganapathysubramanian, Singh, \& Sarkar, 2016), then it could be worth to examine the applicability of DL on these problems too.

Other possible application areas could be the use of aerial imagery (i.e. by means of drones) to monitor the effectiveness of the seeding process, to increase the quality of wine production by harvesting grapes at the right moment for best maturity levels, to monitor animals and their movements to consider their overall welfare and identify possible diseases, and many other scenarios where computer vision is involved.

In spite of the limited availability of open datasets in agriculture, In Appendix III, we list some of the most popular, free to download datasets available on the web, which could be used by researchers to start testing their DL architectures. These datasets could be used to pre-train DL models and then adapt them to more specific future agricultural challenges. In addition to these datasets, remote sensing data containing multi-temporal, multi-spectral and multi-source images that could be used in problems related to land and crop cover classification are available from satellites such as MERIS, MODIS, AVHRR, RapidEye, Sentinel, Landsat etc.

More approaches adopting LSTM or other RNN models are expected in the future, exploiting the time dimension to perform higher performance classification or prediction. An example application could be to estimate the growth of plants, trees or even animals 
based on previous consecutive observations, to predict their yield, assess their water needs or avoid diseases from occurring. These models could find applicability in environmental informatics too, for understanding climatic change, predicting weather conditions and phenomena, estimating the environmental impact of various physical or artificial processes (Kamilaris, Assumpcio, Blasi, Torrellas, \& Prenafeta-Boldú, 2017) etc. Related work under study involved up to a five-unit LSTM model (Minh, et al., 2017). We expect in the future to see more layers stacked together in order to build more complex LSTM architectures (lenco, Gaetano, Dupaquier, \& Maurel, 2017). We also believe that datasets with increasing temporal sequence length will appear, which could improve the performance of LSTM (Rußwurm \& Körner, 2017).

Moreover, more complex architectures would appear, combining various DL models and classifiers together, or combining hand-crafted features with automatic features extracted by using various techniques, fused together to improve the overall outcome, similar to what performed in (Hall, McCool, Dayoub, Sunderhauf, \& Upcroft, 2015) and (Rebetez, J., et al., 2016). Researchers are expected to test their models using more general and realistic dataset, demonstrating the ability of the models to generalize to various real-world situations. A combination of popular performance metrics, such as the ones mentioned in Table 1, are essential to be adopted by the authors for comparison purposes. It would be desirable if researchers made their datasets publicly available, for use also by the general research community.

Finally, some of the solutions discussed in the surveyed papers could have a commercial use in the near future. The approaches incorporating Faster Region-based CNN and DetectNet CNN (Bargoti \& Underwood, 2016), (Chen, et al., 2017), (Rahnemoonfar \& Sheppard, 2017) would be extremely useful for automatic robots that collect crops, remove weeds or for estimating the expected yields of various crops. A future application of this technique could be also in microbiology for human or animal cell counting (Chen, et al., 
2017). The DRNN model controlling the daily feed intake of pigs or chicken, predicting quite accurately the required feed intake for the whole of the growing period, would be useful to farmers when deciding on a growth curve suitable for various scenarios.

Following some growth patterns would have potential advantages for animal welfare in terms of leg health, without compromising the idea animals' final weight and total feed intake requirement (Demmers T. G., et al., 2010), (Demmers T. G., Cao, Parsons, Gauss, \& Wathes, 2012).

\section{Conclusion}

In this paper, we have performed a survey of deep learning-based research efforts applied in the agricultural domain. We have identified 40 relevant papers, examining the particular area and problem they focus on, technical details of the models employed, sources of data used, pre-processing tasks and data augmentation techniques adopted, and overall performance according to the performance metrics employed by each paper. We have then compared deep learning with other existing techniques, in terms of performance. Our findings indicate that deep learning offers better performance and outperforms other popular image processing techniques. For future work, we plan to apply the general concepts and best practices of deep learning, as described through this survey, to other areas of agriculture where this modern technique has not yet been adequately used. Some of these areas have been identified in the discussion section.

Our aim is that this survey would motivate more researchers to experiment with deep learning, applying it for solving various agricultural problems involving classification or prediction, related to computer vision and image analysis, or more generally to data analysis. The overall benefits of deep learning are encouraging for its further use towards smarter, more sustainable farming and more secure food production. 


\section{Acknowledgments}

We would like to thank the reviewers, whose valuable feedback, suggestions and

comments increased significantly the overall quality of this survey. This research has been

supported by the P-SPHERE project, which has received funding from the European

Union's Horizon 2020 research and innovation programme under the Marie Skodowska-

Curie grant agreement No 665919.

\section{References}

Amara, J., Bouaziz, B., \& Algergawy, A. (2017). A Deep Learning-based Approach for Banana Leaf Diseases Classification. (págs. 79-88). Stuttgart: BTW workshop.

Bahrampour, S., Ramakrishnan, N., Schott, L., \& Shah, M. (2015). Comparative study of deep learning software frameworks. arXiv preprint arXiv, 1511(06435).

Bargoti, S., \& Underwood, J. (2016). Deep Fruit Detection in Orchards. arXiv preprint arXiv, 1610(03677).

Bastiaanssen, W., Molden, D., \& Makin, I. (2000). Remote sensing for irrigated agriculture: examples from research and possible applications. Agricultural water management, 46(2), 137-155.

Canziani, A., Paszke, A., \& Culurciello, E. (2016). An Analysis of Deep Neural Network Models for Practical Applications. arXiv preprint arXiv, 1605(07678).

Chen, S. W., Shivakumar, S. S., Dcunha, S., Das, J., Okon, E., Qu, C., \& Kumar, V. (2017). Counting Apples and Oranges With Deep Learning: A Data-Driven Approach. IEEE Robotics and Automation Letters, 2(2), 781-788.

Chen, Y., Lin, Z., Zhao, X., Wang, G., \& Gu, Y. (2014). Deep Learning-Based Classification of Hyperspectral Data. IEEE Journal of Selected topics in applied earth observations and remote sensing, 7(6), 2094-2107.

Chi, M., Plaza, A., Benediktsson, J. A., Sun, Z., Shen, J., \& Zhu, Y. (2016). Big data for remote sensing: challenges and opportunities. Proceedings of the IEEE, 104(11), 2207-2219.

Christiansen, P., Nielsen, L. N., Steen, K. A., Jørgensen, R. N., \& Karstoft, H. (2016). DeepAnomaly: Combining Background Subtraction and Deep Learning for Detecting Obstacles and Anomalies in an Agricultural Field. Sensors , 16(11), 1904.

Demmers, T. G., Cao, Y., Gauss, S., Lowe, J. C., Parsons, D. J., \& Wathes, C. M. (2010). Neural Predictive Control of Broiler Chicken Growth. IFAC Proceedings Volumes, 43(6), 311-316.

Demmers, T. G., Cao, Y., Parsons, D. J., Gauss, S., \& Wathes, C. M. (2012). Simultaneous Monitoring and Control of Pig Growth and Ammonia Emissions. IX International Livestock Environment Symposium (ILES IX). Valencia, Spain: American Society of Agricultural and Biological Engineers.

Deng, J., Dong, W., Socher, R., Li, L. J., Li, K., \& Fei-Fei, L. (2009). Imagenet: A large-scale hierarchical image database. (págs. 248-255). Miami, FL, USA: IEEE Conference on Computer Vision and Pattern Recognition (CVPR).

Deng, L., \& Yu, D. (2014). Deep learning: methods and applications. Foundations and Trends in Signal Processing, 7(3-4), 197-387.

Douarre, C., Schielein, R., Frindel, C., Gerth, S., \& Rousseau, D. (2016). Deep learning based rootsoil segmentation from X-ray tomography. bioRxiv, 071662.

Dyrmann, M., Jørgensen, R. N., \& Midtiby, H. S. (2017). RoboWeedSupport - Detection of weed locations in leaf occluded cereal crops using a fully convolutional neural network. 11th 
European Conference on Precision Agriculture (ECPA). Edinburgh, Scotland.

Dyrmann, M., Karstoft, H., \& Midtiby, H. S. (2016 ). Plant species classification using deep convolutional neural network. Biosystems Engineering, 151, 72-80.

Dyrmann, M., Mortensen, A. K., Midtiby, H. S., \& Jørgensen, R. N. (2016). Pixel-wise classification of weeds and crops in images by using a fully convolutional neural network. International Conference on Agricultural Engineering. Aarhus, Denmark.

FAO. (2009). How to Feed the World in 2050. Rome: Food and Agriculture Organization of the United Nations.

Gebbers, R., \& Adamchuk, V. I. (2010). Precision agriculture and food security. Science, $327(5967), 828-831$.

Gers, F. A., Schmidhuber, J., \& Cummins, F. (2000). Learning to forget: Continual prediction with LSTM. Neural Computation, 12(10), 2451-2471.

Grinblat, G. L., Uzal, L. C., Larese, M. G., \& Granitto, P. M. (2016). Deep learning for plant identification using vein morphological patterns. Computers and Electronics in Agriculture, $127,418-424$.

Hall, D., McCool, C., Dayoub, F., Sunderhauf, N., \& Upcroft, B. (2015). Evaluation of features for leaf classification in challenging conditions. Winter Conference on Applications of Computer Vision (WACV) (págs. 797-804). Waikoloa Beach, Hawaii: IEEE.

Hashem, I., Yaqoob, I., Anuar, N., Mokhtar, S., Gani, A., \& Khan, S. (2015). The rise of "big data" on cloud computing: Review and open research issues. Information Systems, 47, 98-115.

Ienco, D., Gaetano, R., Dupaquier, C., \& Maurel, P. (2017). Land Cover Classification via Multitemporal Spatial Data by Recurrent Neural Networks. arXiv preprint arXiv:1704.04055.

Ishimwe, R., Abutaleb, K., \& Ahmed, F. (2014). Applications of thermal imaging in agriculture-A review. Advances in Remote Sensing, 3(3), 128.

Jia, Y., Shelhamer, E., Donahue, J., Karayev, S., Long, J., Girshick, R., . . Darrell, T. (2014). Caffe: Convolutional architecture for fast feature embedding. Proceedings of the 22nd International Conference on Multimedia (págs. 675-678). Orlando, FL, USA: ACM.

Kamilaris, A., Assumpcio, A., Blasi, A. B., Torrellas, M., \& Prenafeta-Boldú, F. X. (2017). Estimating the Environmental Impact of Agriculture by Means of Geospatial and Big Data Analysis: The Case of Catalonia. From Science to Society (págs. 39-48). Luxembourg: Springer.

Kamilaris, A., Gao, F., Prenafeta-Boldú, F. X., \& Ali, M. I. (2016). Agri-IoT: A semantic framework for Internet of Things-enabled smart farming applications. 3rd World Forum on Internet of Things (WF-IoT) (págs. 442-447). Reston, VA, USA: IEEE.

Kamilaris, A., Kartakoullis, A., \& Prenafeta-Boldú, F. X. (2017). A review on the practice of big data analysis in agriculture. Computers and Electronics in Agriculture, 143(1), 23-37.

Kitzes, J., Wackernagel, M., Loh, J., Peller, A., Goldfinger, S., Cheng, D., \& Tea, K. (2008). Shrink and share: humanity's present and future Ecological Footprint. Philosophical Transactions of the Royal Society of London B: Biological Sciences, 363(1491), 467-475.

Krizhevsky, A., Sutskever, I., \& Hinton, G. E. (2012). Imagenet classification with deep convolutional neural networks. Advances in neural information processing systems, 10971105.

Kussul, N., Lavreniuk, M., Skakun, S., \& Shelestov, A. (2017). Deep Learning Classification of Land Cover and Crop Types Using Remote Sensing Data. IEEE Geoscience and Remote Sensing Letters, 14(5), 778-782.

Kuwata, K., \& Shibasaki, R. (2015). Estimating crop yields with deep learning and remotely sensed data. (págs. 858-861). Milan, Italy: IEEE International Geoscience and Remote Sensing Symposium (IGARSS).

LeCun, Y., \& Bengio, Y. (1995). Convolutional networks for images, speech, and time series. The handbook of brain theory and neural networks, 3361(10).

LeCun, Y., Bengio, Y., \& Hinton, G. (2015). Deep learning. Nature, 521(7553), 436-444.

Lee, S. H., Chan, C. S., Wilkin, P., \& Remagnino, P. (2015). Deep-plant: Plant identification with 
convolutional neural networks. (págs. 452-456). Quebec city, Canada: IEEE International Conference on Image Processing (ICIP).

Liaghat, S., \& Balasundram, S. K. (2010). A review: The role of remote sensing in precision agriculture. American journal of agricultural and biological sciences, 5(1), 50-55.

Lu, H., Fu, X., Liu, C., Li, L. G., He, Y. X., \& Li, N. W. (2017). Cultivated land information extraction in UAV imagery based on deep convolutional neural network and transfer learning. Journal of Mountain Science, 14(4), 731-741.

Luus, F. P., Salmon, B. P., van den Bergh, F., \& Maharaj, B. T. (2015). Multiview deep learning for land-use classification. IEEE Geoscience and Remote Sensing Letters, 12(12), 2448-2452.

Mandic, D. P., \& Chambers, J. A. (2001). Recurrent neural networks for prediction: learning algorithms, architectures and stability. New York: John Wiley.

McCool, C., Perez, T., \& Upcroft, B. (2017). Mixtures of Lightweight Deep Convolutional Neural Networks: Applied to Agricultural Robotics. IEEE Robotics and Automation Letters, 2(3), 1344-1351.

Milioto, A., Lottes, P., \& Stachniss, C. (2017). Real-time blob-wise sugar beets vs weeds classification for monitoring fields using convolutional neural networks. Proceedings of the International Conference on Unmanned Aerial Vehicles in Geomatics. Bonn, Germany.

Minh, D. H., Ienco, D., Gaetano, R., Lalande, N., Ndikumana, E., Osman, F., \& Maurel, P. (2017). Deep Recurrent Neural Networks for mapping winter vegetation quality coverage via multitemporal SAR Sentinel-1. arXiv preprint arXiv:1708.03694.

Mohanty, S. P., Hughes, D. P., \& Salathé, M. (2016). Using deep learning for image-based plant disease detection. Frontiers in plant science, 7.

Mortensen, A. K., Dyrmann, M., Karstoft, H., Jørgensen, R. N., \& Gislum, R. (2016). Semantic segmentation of mixed crops using deep convolutional neural network. International Conference on Agricultural Engineering. Aarhus, Denmark.

Najafabadi, M. M., Villanustre, F., Khoshgoftaar, T. M., Seliya, N., Wald, R., \& Muharemagic, E. (2015). Deep learning applications and challenges in big data analytics. Journal of Big Data, 2(1), 1 .

Namin, S. T., Esmaeilzadeh, M., Najafi, M., Brown, T. B., \& Borevitz, J. O. (2017). Deep Phenotyping: Deep Learning For Temporal Phenotype/Genotype Classification. bioRxiv, 134205.

Ozdogan, M., Yang, Y., Allez, G., \& Cervantes, C. (2010). Remote sensing of irrigated agriculture: Opportunities and challenges. Remote sensing, 2(9), 2274-2304.

Pan, S. J., \& Yang, Q. (2010). A survey on transfer learning. IEEE Transactions on knowledge and data engineering , 22(10), 1345-1359.

PASCAL VOC Project. (2012). The PASCAL Visual Object Classes. Obtenido de http://host.robots.ox.ac.uk/pascal/VOC/

Potena, C., Nardi, D., \& Pretto, A. (2016). Fast and accurate crop and weed identification with summarized train sets for precision agriculture. International Conference on Intelligent Autonomous Systems (págs. 105-121). Shanghai, China: Springer, Cham.

Pound, M. P., et al. (2016). Deep Machine Learning provides state-of-the-art performance in image-based plant phenotyping. bioRxiv, 053033.

Rahnemoonfar, M., \& Sheppard, C. (2017). Deep Count: Fruit Counting Based on Deep Simulated Learning. Sensors, 17(4), 905.

Rebetez, J., et al. (2016). Augmenting a convolutional neural network with local histograms-a case study in crop classification from high-resolution UAV imagery. European Symposium on Artificial Neural Networks, Computational Intelligence and Machine Learning. Bruges, Belgium.

Reyes, A. K., Caicedo, J. C., \& Camargo, J. E. (2015). Fine-tuning Deep Convolutional Networks for Plant Recognition. Toulouse: CLEF (Working Notes).

Rußwurm, M., \& Körner, M. (2017). Multi-Temporal Land Cover Classification with Long ShortTerm Memory Neural Networks. International Archives of the Photogrammetry, Remote 
Sensing \& Spatial Information Sciences, 42.

Sa, I., Ge, Z., Dayoub, F., Upcroft, B., Perez, T., \& McCool, C. (2016). Deepfruits: A fruit detection system using deep neural networks. Sensors, 16(8), 1222.

Santoni, M. M., Sensuse, D. I., Arymurthy, A. M., \& Fanany, M. I. (2015). Cattle Race Classification Using Gray Level Co-occurrence Matrix Convolutional Neural Networks. Procedia Computer Science, 59, 493-502.

Saxena, L., \& Armstrong, L. (2014). A survey of image processing techniques for agriculture. Perth, Australia: Proceedings of Asian Federation for Information Technology in Agriculture, Australian Society of Information and Communication Technologies in Agriculture.

Schmidhuber, J. (2015). Deep learning in neural networks: An overview. Neural networks, 61, 85117.

Sehgal, G., Gupta, B., Paneri, K., Singh, K., Sharma, G., \& Shroff, G. (2017). Crop Planning using Stochastic Visual Optimization. arXiv preprint arXiv:1710.09077.

Simonyan, K., \& Zisserman, A. (2014). Very deep convolutional networks for large-scale image recognition. arXiv preprint arXiv, 1409(1556).

Singh, A., Ganapathysubramanian, B., Singh, A. K., \& Sarkar, S. (2016). Machine Learning for High-Throughput Stress Phenotyping in Plants. Trends in Plant Science, 21(2), 110-124.

Sladojevic, S., Arsenovic, M., Anderla, A., Culibrk, D., \& Stefanovic, D. (2016). Deep neural networks based recognition of plant diseases by leaf image classification. Computational intelligence and neuroscience, 2016.

Song, X., Zhang, G., Liu, F., Li, D., Zhao, Y., \& Yang, J. (2016). Modeling spatio-temporal distribution of soil moisture by deep learning-based cellular automata model. Journal of Arid Land, 8(5), 734-748.

Sørensen, R. A., Rasmussen, J., Nielsen, J., \& Jørgensen, R. (2017). Thistle detection using convolutional neural networks. Montpellier, France: EFITA Congress.

Steen, K. A., Christiansen, P., Karstoft, H., \& Jørgensen, R. N. (2016). Using Deep Learning to Challenge Safety Standard for Highly Autonomous Machines in Agriculture. Journal of Imaging, 2(1), 6.

Szegedy, C., Ioffe, S., Vanhoucke, V., \& Alemi, A. A. (2017). Inception-v4, Inception-ResNet and the Impact of Residual Connections on Learning. (págs. 4278-4284). AAAI.

Szegedy, C., Liu, W., Jia, Y., Sermanet, P., Reed, S., Anguelov, D., \& Rabinovich, A. (2015). Going deeper with convolutions. (págs. 1-9). Boston, MA, USA: IEEE conference on computer vision and pattern recognition.

Teke, M., Deveci, H. S., Haliloğlu, O., Gürbüz, S. Z., \& Sakarya, U. (2013). A short survey of hyperspectral remote sensing applications in agriculture. Istanbul, Turkey: 6th International Conference on Recent Advances in Space Technologies (RAST), IEEE.

Tyagi, A. C. (2016). Towards a Second Green Revolution. Irrigation and Drainage, 65(4), 388389.

Waga, D., \& Rabah, K. (2014). Environmental conditions' big data management and cloud computing analytics for sustainable agriculture. World Journal of Computer Application and Technology, 2(3), 73-81.

Wan, J., Wang, D., Hoi, S. C., Wu, P., Zhu, J., Zhang, Y., \& Li, J. (2014). Deep learning for content-based image retrieval: A comprehensive study. (págs. 157-166). Orlando, FL: Proceedings of the 22nd ACM international conference on Multimedia, ACM.

Weber, R. H., \& Weber, R. (2010). Internet of Things (Vol. 12). New York, NY, USA: Springer.

Xinshao, W., \& Cheng, C. (2015). Weed seeds classification based on PCANet deep learning baseline. (págs. 408-415). IEEE Signal and Information Processing Association Annual Summit and Conference (APSIPA).

Yalcin, H. (2017) ). Plant phenology recognition using deep learning: Deep-Pheno. 6th International Conference on Agro-Geoinformatics. Fairfax VA, USA. 
Appendix I: Applications of computer vision in agriculture and popular techniques used.

\begin{tabular}{|c|c|c|c|}
\hline No. & $\begin{array}{l}\text { Application in } \\
\text { Agriculture }\end{array}$ & Remote sensing & Techniques for data analysis \\
\hline 1. & $\begin{array}{l}\text { Soil and } \\
\text { vegetation/crop } \\
\text { mapping }\end{array}$ & $\begin{array}{l}\text { Hyperspectral imaging } \\
\text { (satellite and airborne), } \\
\text { multi-spectral imaging } \\
\text { (satellite), synthetic } \\
\text { aperture radar (SAR) }\end{array}$ & $\begin{array}{l}\text { Image fusion, SVM, end-member extraction algorithm, } \\
\text { co-polarized phase differences (PPD), linear } \\
\text { polarizations (HH, VV, HV), distance-based } \\
\text { classification, decision trees, linear mixing models, } \\
\text { logistic regression, ANN, NDVI }\end{array}$ \\
\hline 2. & $\begin{array}{l}\text { Leaf area index } \\
\text { and crop canopy }\end{array}$ & $\begin{array}{l}\text { Hyperspectral imaging } \\
\text { (airborne), multi-spectral } \\
\text { imaging (airborne) }\end{array}$ & Linear regression analysis, NDVI \\
\hline 3. & Crop phenology & $\begin{array}{l}\text { Satellite remote sensing } \\
\text { (general) }\end{array}$ & Wavelet-based filtering, Fourier transforms, NDVI \\
\hline 4. & $\begin{array}{l}\text { Crop height, } \\
\text { estimation of } \\
\text { yields, fertilizers' } \\
\text { effect and } \\
\text { biomass }\end{array}$ & $\begin{array}{l}\text { Light Detection and } \\
\text { Ranging (LIDAR), } \\
\text { hyperspectral and multi- } \\
\text { spectral imaging, SAR, } \\
\text { red-edge camera, } \\
\text { thermal infrared }\end{array}$ & $\begin{array}{l}\text { Linear and exponential regression analysis, linear } \\
\text { polarizations (VV), wavelet-based filtering, vegetation } \\
\text { indices (NDVI, ICWSI), ANN }\end{array}$ \\
\hline 5. & Crop monitoring & $\begin{array}{l}\text { Satellite remote sensing, } \\
\text { (hyperspectral and multi- } \\
\text { spectral imaging), NIR } \\
\text { camera, SAR }\end{array}$ & $\begin{array}{l}\text { Stepwise discriminate analysis (DISCRIM) feature } \\
\text { extraction, linear regression analysis, co-polarized phase } \\
\text { differences (PPD), linear polarizations (HH, VV, HV, RR } \\
\text { and RL), classification and regression tree analysis }\end{array}$ \\
\hline 6. & $\begin{array}{l}\text { Identification of } \\
\text { seeds and } \\
\text { reorganization of } \\
\text { species }\end{array}$ & $\begin{array}{l}\text { Remote sensing in } \\
\text { general, cameras and } \\
\text { photo-detectors, } \\
\text { hyperspectral imaging }\end{array}$ & $\begin{array}{l}\text { Principal component analysis, feature extraction, linear } \\
\text { regression analysis }\end{array}$ \\
\hline 7. & $\begin{array}{l}\text { Soil and leaf } \\
\text { nitrogen content } \\
\text { and treatment, } \\
\text { salinity detection }\end{array}$ & $\begin{array}{l}\text { Hyperspectral and multi- } \\
\text { spectral imaging, thermal } \\
\text { imaging }\end{array}$ & Linear and exponential regression analysis \\
\hline 8. & Irrigation & $\begin{array}{l}\text { Satellite remote sensing } \\
\text { (hyperspectral and multi- } \\
\text { spectral imaging), red- } \\
\text { edge camera, thermal } \\
\text { infrared }\end{array}$ & $\begin{array}{l}\text { Image classification techniques (unsupervised } \\
\text { clustering, density slicing with thresholds), decision } \\
\text { trees, linear regression analysis, NDVI }\end{array}$ \\
\hline 9. & $\begin{array}{l}\text { Plants water } \\
\text { stress detection } \\
\text { and drought } \\
\text { conditions }\end{array}$ & $\begin{array}{l}\text { Satellite remote sensing } \\
\text { (hyperspectral and multi- } \\
\text { spectral imaging, radar } \\
\text { images), thermal } \\
\text { imaging, NIR camera, } \\
\text { red-edge camera }\end{array}$ & $\begin{array}{l}\text { Fraunhofer Line Depth (FLD) principle, linear regression } \\
\text { analysis, NDVI }\end{array}$ \\
\hline 10. & $\begin{array}{l}\text { Water erosion } \\
\text { assessment }\end{array}$ & $\begin{array}{l}\text { Satellite remote sensing } \\
\text { (optical and radar } \\
\text { images), SAR, NIR } \\
\text { camera }\end{array}$ & $\begin{array}{l}\text { Interferometric SAR image processing, linear and } \\
\text { exponential regression analysis, contour tracing, linear } \\
\text { polarizations }(\mathrm{HH}, \mathrm{VV})\end{array}$ \\
\hline
\end{tabular}




\begin{tabular}{|c|c|c|c|}
\hline 11. & $\begin{array}{l}\text { Pest detection } \\
\text { and } \\
\text { management }\end{array}$ & $\begin{array}{l}\text { Hyperspectral and multi- } \\
\text { spectral imaging, } \\
\text { microwave remote } \\
\text { sensing, thermal camera }\end{array}$ & $\begin{array}{l}\text { Image processing using sample imagery, linear and } \\
\text { exponential regression analysis, statistical analysis, } \\
\text { CEM nonlinear signal processing, NDVI }\end{array}$ \\
\hline 12. & Weed detection & $\begin{array}{l}\text { Remote sensing in } \\
\text { general, optical cameras } \\
\text { and photo-detectors, } \\
\text { hyperspectral and multi- } \\
\text { spectral imaging }\end{array}$ & $\begin{array}{l}\text { Pixel classification based on k-means clustering and } \\
\text { Bayes classifier, feature extraction techniques with FFT } \\
\text { and GLCM, wavelet-based classification and Gabor } \\
\text { filtering, genetic algorithms, fuzzy techniques, artificial } \\
\text { neural networks, erosion and dilation segmentation, } \\
\text { logistic regression, edge detection, color detection, } \\
\text { principal component analysis }\end{array}$ \\
\hline 13. & Herbicide & $\begin{array}{l}\text { Remote sensing in } \\
\text { general, optical cameras } \\
\text { and photo-detectors }\end{array}$ & Fuzzy techniques, discriminant analysis \\
\hline 14. & Fruit grading & $\begin{array}{l}\text { Optical cameras and } \\
\text { photo-detectors, } \\
\text { monochrome images } \\
\text { with different } \\
\text { illuminations }\end{array}$ & $\begin{array}{l}\text { K-means clustering, image fusion, color histogram } \\
\text { techniques, machine learning (esp. SVM), Bayesian } \\
\text { discriminant analysis, Bayes filtering, linear discriminant } \\
\text { analysis }\end{array}$ \\
\hline 15. & $\begin{array}{l}\text { Packaged food } \\
\text { and food } \\
\text { products - } \\
\text { identification of } \\
\text { contaminants, } \\
\text { diseases or } \\
\text { defects, bruise } \\
\text { detection }\end{array}$ & $\begin{array}{l}\text { X-ray imaging (or } \\
\text { transmitted light), CCD } \\
\text { cameras, monochrome } \\
\text { images with different } \\
\text { illuminations, thermal } \\
\text { cameras, multi-spectral } \\
\text { and hyperspectral NIR- } \\
\text { based imaging }\end{array}$ & $\begin{array}{l}\text { 3D vision, invariance, pattern recognition and image } \\
\text { modality, multivariate image analysis with principal } \\
\text { component analysis, K-mean clustering, SVM, linear } \\
\text { discriminant analysis, classification trees, K-nearest } \\
\text { neighbors, decision trees, fusion, feature extraction } \\
\text { techniques with FFT, standard Bayesian discriminant } \\
\text { analysis, feature analysis, color, shape and geometric } \\
\text { features using discrimination analysis, pulsed-phase } \\
\text { thermography }\end{array}$ \\
\hline 16. & $\begin{array}{l}\text { Crop hail } \\
\text { damage }\end{array}$ & $\begin{array}{l}\text { Multi-spectral imaging, } \\
\text { polarimetric radar } \\
\text { imagery }\end{array}$ & $\begin{array}{l}\text { Linear and exponential regression analysis, } \\
\text { unsupervised image classification }\end{array}$ \\
\hline 17. & $\begin{array}{l}\text { Agricultural } \\
\text { expansion and } \\
\text { intensification }\end{array}$ & $\begin{array}{l}\text { Satellite remote sensing } \\
\text { in general }\end{array}$ & Wavelet-based filtering \\
\hline 18. & $\begin{array}{l}\text { Greenhouse } \\
\text { monitoring }\end{array}$ & $\begin{array}{l}\text { Optical and thermal } \\
\text { cameras }\end{array}$ & $\begin{array}{l}\text { Linear and exponential regression analysis, } \\
\text { unsupervised classification, NDVI, IR thermography }\end{array}$ \\
\hline
\end{tabular}


Appendix II: Applications of deep learning in agriculture.

\begin{tabular}{|c|c|c|c|c|c|c|c|c|c|c|c|c|c|c|}
\hline No. & $\begin{array}{l}\text { Agri } \\
\text { Area }\end{array}$ & $\begin{array}{l}\text { Problem } \\
\text { Description }\end{array}$ & Data Used & $\begin{array}{l}\text { Classes and } \\
\text { Labels }\end{array}$ & $\begin{array}{c}\text { Variation } \\
\text { among } \\
\text { Classes }\end{array}$ & $\begin{array}{c}\text { DL } \\
\text { Model } \\
\text { Used }\end{array}$ & $\begin{array}{l}\text { FW } \\
\text { Used }\end{array}$ & $\begin{array}{l}\text { Data Pre- } \\
\text { Processing }\end{array}$ & $\begin{array}{c}\text { Data } \\
\text { augmenta } \\
\text { tion }\end{array}$ & $\begin{array}{l}\text { Data for } \\
\text { Training } \\
\text { vs. } \\
\text { Testing }\end{array}$ & $\begin{array}{l}\text { Perfor } \\
\text { mance } \\
\text { Metric } \\
\text { Used }\end{array}$ & $\begin{array}{c}\text { Value of } \\
\text { Metric } \\
\text { Used }\end{array}$ & $\begin{array}{l}\text { Comparison } \\
\text { with other } \\
\text { technique }\end{array}$ & Ref. \\
\hline 1. & 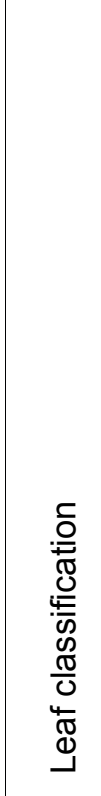 & $\begin{array}{l}\text { Classify } \\
\text { leaves of } \\
\text { different } \\
\text { plant species }\end{array}$ & $\begin{array}{l}\text { Flavia dataset, } \\
\text { consisting of } 1,907 \\
\text { leaf images of } 32 \\
\text { species with at } \\
\text { least } 50 \text { images } \\
\text { per species and at } \\
\text { most } 77 \text { images. }\end{array}$ & $\begin{array}{l}32 \text { classes: } 32 \\
\text { Different plant } \\
\text { species }\end{array}$ & $\mathrm{N} / \mathrm{A}$ & $\begin{array}{c}\text { Author- } \\
\text { defined } \\
\text { CNN + } \\
\text { RF } \\
\text { classifier }\end{array}$ & Caffe & $\begin{array}{c}\text { Feature } \\
\text { extraction } \\
\text { based on } \\
\text { Histograms of } \\
\text { Curvature } \\
\text { over Scale } \\
\text { (HoCS), } \\
\text { shape and } \\
\text { statistical } \\
\text { features, use } \\
\text { of normalized } \\
\text { excessive } \\
\text { green (NExG) } \\
\text { vegetative } \\
\text { index, white } \\
\text { border } \\
\text { doubling } \\
\text { image size, } \\
\text { segmentation }\end{array}$ & $\mathrm{N} / \mathrm{A}$ & $\begin{array}{c}\text { Same. } \\
\text { (condition } \\
\text { variations } \\
\text { applied in } \\
\text { testing: } \\
\text { translations, } \\
\text { scaling, } \\
\text { rotations, } \\
\text { shading and } \\
\text { occlusions) }\end{array}$ & CA & $\begin{array}{l}97.3 \% \\
\pm 0.6 \%\end{array}$ & $\begin{array}{l}\text { Feature } \\
\text { extraction } \\
\text { (shape and } \\
\text { statistical } \\
\text { features) and } \\
\text { RF classifier } \\
(91.2 \% \pm \\
1.6 \%)\end{array}$ & $\begin{array}{l}\text { (Hall, } \\
\text { McCool, } \\
\text { Dayoub, } \\
\text { Sunderha } \\
\text { uf, \& } \\
\text { Upcroft, } \\
\text { 2015) }\end{array}$ \\
\hline 2. & 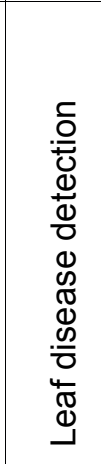 & $\begin{array}{l}13 \text { different } \\
\text { types of } \\
\text { plant } \\
\text { diseases out } \\
\text { of healthy } \\
\text { leaves }\end{array}$ & $\begin{array}{l}\text { Authors-created } \\
\text { database } \\
\text { containing } 4,483 \\
\text { images. }\end{array}$ & $\begin{array}{l}15 \text { classes: } \\
\text { Plant diseases } \\
\text { (13), healthy } \\
\text { leaves (1) and } \\
\text { background } \\
\text { images (1) }\end{array}$ & $\mathrm{N} / \mathrm{A}$ & $\begin{array}{c}\text { CaffeNet } \\
\text { CNN }\end{array}$ & Caffe & $\begin{array}{l}\text { Cropping, } \\
\text { square around } \\
\text { the leaves to } \\
\text { highlight } \\
\text { region of } \\
\text { interest, } \\
\text { resized to } \\
256 \times 256 \text { pix, } \\
\text { dupl. image } \\
\text { removal }\end{array}$ & $\begin{array}{c}\text { Affine } \\
\text { transform } \\
\text { (translation, } \\
\text { rotation), } \\
\text { perspective } \\
\text { transform, } \\
\text { and image } \\
\text { rotations. }\end{array}$ & Same & CA & $96.30 \%$ & $\begin{array}{l}\text { Better results } \\
\text { than SVM (no } \\
\text { more details) }\end{array}$ & $\begin{array}{l}\text { (Sladojevi } \\
\text { c, } \\
\text { Arsenovic } \\
\text {, Anderla, } \\
\text { Culibrk, \& } \\
\text { Stefanovi } \\
\text { c, 2016) }\end{array}$ \\
\hline
\end{tabular}




\begin{tabular}{|c|c|c|c|c|c|c|c|c|c|c|c|c|c|c|}
\hline 3. & \multirow{2}{*}{ 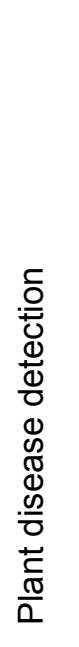 } & $\begin{array}{l}\text { Identify } 14 \\
\text { crop species } \\
\text { and } 26 \\
\text { diseases }\end{array}$ & $\begin{array}{l}\text { PlantVillage public } \\
\text { dataset of } 54,306 \\
\text { images of } \\
\text { diseased and } \\
\text { healthy plant } \\
\text { leaves collected } \\
\text { under controlled } \\
\text { conditions. }\end{array}$ & $\begin{array}{l}38 \text { class labels } \\
\text { as crop- } \\
\text { disease pairs }\end{array}$ & N/A & $\begin{array}{l}\text { AlexNet, } \\
\text { GoogleN } \\
\text { et CNNs }\end{array}$ & Caffe & $\begin{array}{l}\text { Resized to } \\
256 \times 256 \text { pix., } \\
\text { segmentation, } \\
\text { background } \\
\text { Information } \\
\text { removal, fixed } \\
\text { color casts }\end{array}$ & $\mathrm{N} / \mathrm{A}$ & \begin{tabular}{|} 
Same. Also \\
tested on a \\
dataset of \\
downloaded \\
images \\
from Bing \\
Image \\
Search and \\
IPM Images
\end{tabular} & F1 & 0.9935 & $\begin{array}{l}\text { Substantial } \\
\text { margin in } \\
\text { standard } \\
\text { benchmarks } \\
\text { with } \\
\text { approaches } \\
\text { using hand- } \\
\text { engineered } \\
\text { features }\end{array}$ & $\begin{array}{l}\text { (Mohanty, } \\
\text { Hughes, } \\
\text { \& } \\
\text { Salathé, } \\
2016)\end{array}$ \\
\hline 4. & & $\begin{array}{l}\text { Classify } \\
\text { banana } \\
\text { leaves' } \\
\text { diseases }\end{array}$ & $\begin{array}{l}\text { Dataset of } 3,700 \\
\text { images of banana } \\
\text { diseases obtained } \\
\text { from the } \\
\text { PlantVillage } \\
\text { dataset. }\end{array}$ & $\begin{array}{l}3 \text { classes: } \\
\text { healthy, } \\
\text { black sigatoka } \\
\text { and black } \\
\text { speckle }\end{array}$ & N/A & $\begin{array}{l}\text { LeNet } \\
\text { CNN }\end{array}$ & $\begin{array}{c}\text { deeplear } \\
\text { ning4j }\end{array}$ & $\begin{array}{l}\text { Resized to } \\
60 x 60 \text { pix., } \\
\text { converted to } \\
\text { grayscale }\end{array}$ & N/A & Same & CA, F1 & $\begin{array}{l}96+\% \\
(\mathrm{CA}), \\
0.968 \\
(\mathrm{~F} 1)\end{array}$ & $\begin{array}{l}\text { Methods } \\
\text { using hand- } \\
\text { crafted } \\
\text { features not } \\
\text { generalize } \\
\text { well }\end{array}$ & $\begin{array}{l}\text { (Amara, } \\
\text { Bouaziz, } \\
\& \\
\text { Algergaw } \\
\text { y, 2017) }\end{array}$ \\
\hline 5. & & $\begin{array}{l}\text { Identify } 13 \\
\text { different } \\
\text { land-cover } \\
\text { classes in } \\
\text { KSC and } 9 \\
\text { different } \\
\text { classes in } \\
\text { Pavia }\end{array}$ & $\begin{array}{l}\text { A mixed } \\
\text { vegetation site } \\
\text { over Kennedy } \\
\text { Space Center } \\
\text { (KSC), FL, USA } \\
\text { (Dataset 1), and } \\
\text { an urban site over } \\
\text { the city of Pavia, } \\
\text { Italy (Dataset 2). } \\
\text { Hyperspectral } \\
\text { datasets. }\end{array}$ & $\begin{array}{l}13 \text { different } \\
\text { land-cover } \\
\text { classes } \\
\text { (Dataset 1), } 9 \\
\text { land cover } \\
\text { classes trees } \\
\text { (Dataset 2): } \\
\text { Soil, meadow, } \\
\text { water, } \\
\text { shadows, } \\
\text { different } \\
\text { materials }\end{array}$ & N/A & $\begin{array}{l}\text { Hybrid of } \\
\text { PCA, } \\
\text { autoenc } \\
\text { oder } \\
(\mathrm{AE}), \\
\text { and } \\
\text { logistic } \\
\text { regressi } \\
\text { on }\end{array}$ & $\begin{array}{l}\text { Develop } \\
\text { ed by } \\
\text { the } \\
\text { authors }\end{array}$ & $\begin{array}{l}\text { Some bands } \\
\text { removed due } \\
\text { to noise }\end{array}$ & N/A & Same & CA & $98.70 \%$ & $\begin{array}{l}1 \% \text { more } \\
\text { precise than } \\
\text { RBF-SVM }\end{array}$ & $\begin{array}{l}\text { (Chen, } \\
\text { Lin, Zhao, } \\
\text { Wang, \& } \\
\text { Gu, 2014) }\end{array}$ \\
\hline 6. & 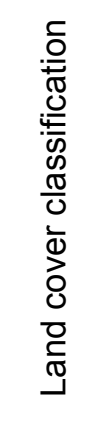 & $\begin{array}{l}\text { Identify } 21 \\
\text { land-use } \\
\text { classes } \\
\text { containing a } \\
\text { variety of } \\
\text { spatial } \\
\text { patterns }\end{array}$ & $\begin{array}{l}\text { UC Merced land- } \\
\text { use data set. } \\
\text { Aerial ortho- } \\
\text { imagery with a } \\
0.3048-m \text { pixel } \\
\text { resolution. Dataset } \\
\text { compiled from a } \\
\text { selection of } 100 \\
\text { images/class. }\end{array}$ & $\begin{array}{l}21 \text { land-use } \\
\text { classes: } \\
\text { Agricultural, } \\
\text { airplane, } \\
\text { sports, beach, } \\
\text { buildings, } \\
\text { residential, } \\
\text { forest, freeway, } \\
\text { harbor, parking } \\
\text { lot, river etc. }\end{array}$ & $\begin{array}{l}\text { High relevance } \\
\text { between } \\
\text { medium density } \\
\text { and dense } \\
\text { residential, as } \\
\text { well as between } \\
\text { buildings and } \\
\text { storage tanks }\end{array}$ & \begin{tabular}{|c|} 
Author- \\
defined \\
$\mathrm{CNN}+$ \\
multiview \\
model \\
averaging
\end{tabular} & Theano & $\begin{array}{l}\text { From RGB to } \\
\text { HSV (hue- } \\
\text { saturation- } \\
\text { value) color } \\
\text { model, } \\
\text { resized to } \\
96 \times 96 \text { pix., } \\
\text { creation of } \\
\text { multiscale } \\
\text { views }\end{array}$ & $\begin{array}{l}\text { Views } \\
\text { flipped } \\
\text { horizontally } \\
\text { or vertically } \\
\text { with a } \\
\text { probability } \\
\text { of } 0.5\end{array}$ & Same & CA & $93.48 \%$ & $\begin{array}{l}\text { Unsupervised } \\
\text { feature } \\
\text { learning } \\
\text { (UFL): } 82- \\
90 \% \\
\text { SIFT: } 85 \%\end{array}$ & $\begin{array}{l}\text { (Luus, } \\
\text { Salmon, } \\
\text { van den } \\
\text { Bergh, \& } \\
\text { Maharaj, } \\
\text { 2015) }\end{array}$ \\
\hline
\end{tabular}




\begin{tabular}{|c|c|c|c|c|c|c|c|c|c|c|c|c|c|c|}
\hline 7. & & $\begin{array}{l}\text { Extract } \\
\text { information } \\
\text { about } \\
\text { cultivated } \\
\text { land }\end{array}$ & $\begin{array}{l}\text { Images from UAV } \\
\text { at the areas } \\
\text { Pengzhou County } \\
\text { and Guanghan } \\
\text { County, Sichuan } \\
\text { Province, China. }\end{array}$ & $\begin{array}{l}2 \text { classes: } \\
\text { Cultivated vs. } \\
\text { non-cultivated }\end{array}$ & $\begin{array}{l}\text { The cultivated } \\
\text { land samples } \\
\text { and part of } \\
\text { forest land } \\
\text { samples were } \\
\text { easily confused }\end{array}$ & $\begin{array}{l}\text { Author- } \\
\text { defined } \\
\text { CNN }\end{array}$ & $\mathrm{N} / \mathrm{A}$ & \begin{tabular}{|} 
Orthorectificati \\
on, image \\
matching, \\
linear land \\
elimination, \\
correct \\
distortion, \\
zoomed to \\
$40 \times 40$ pix.
\end{tabular} & N/A & Same & $\mathrm{CA}$ & $88-91 \%$ & $\mathrm{~N} / \mathrm{A}$ & $\begin{array}{l}\text { (Lu, et al., } \\
2017)\end{array}$ \\
\hline 8. & & $\begin{array}{l}\text { Land cover } \\
\text { classification } \\
\text { considering } \\
\text { time series }\end{array}$ & $\begin{array}{l}\text { First dataset } \\
\text { generated using a } \\
\text { time series of } \\
\text { Pléiades VHSR } \\
\text { images at THAU } \\
\text { Basin. Second } \\
\text { dataset generated } \\
\text { from an annual } \\
\text { time series of } 23 \\
\text { Landsat } 8 \text { images } \\
\text { acquired in } 2014 \\
\text { above Reunion } \\
\text { Island. }\end{array}$ & $\begin{array}{l}11 \text { classes } \\
\text { (dataset 1), } \\
9 \text { classes } \\
\text { (dataset 2). } \\
\text { Land cover } \\
\text { classes such } \\
\text { as trees, crops, } \\
\text { forests, water, } \\
\text { soils, urban } \\
\text { areas, } \\
\text { grasslands, } \\
\text { etc. (Image } \\
\text { object or pixel) }\end{array}$ & $\begin{array}{l}\text { Tree Crops, } \\
\text { Summer crops } \\
\text { and Truck } \\
\text { Farming were } \\
\text { classes highly } \\
\text { mixed }\end{array}$ & $\begin{array}{l}\text { One-unit } \\
\text { LSTM + } \\
\text { RFF, } \\
\text { One-unit } \\
\text { LSTM + } \\
\text { SVM }\end{array}$ & $\begin{array}{l}\text { Keras/ } \\
\text { Theano }\end{array}$ & \begin{tabular}{|} 
Multiresolution \\
segmentation \\
technique, \\
feature \\
extraction, \\
pixel-wise \\
multi-temporal \\
linear \\
interpolation, \\
various \\
radiometric \\
indices \\
calculated
\end{tabular} & N/A & Same & $\mathrm{CA}, \mathrm{F} 1$ & $\begin{array}{l}\text { First } \\
\text { Dataset: } \\
75.34 \% \\
(\text { CA), } \\
0.7463 \\
\text { (F1) } \\
\text { Second } \\
\text { Dataset: } \\
84.61 \% \\
\text { (CA), } \\
0.8441 \\
\text { (F1) }\end{array}$ & $\begin{array}{l}\text { RF and SVM } \\
\text { (best of both): } \\
\text { First Dataset: } \\
74.20 \%(\mathrm{CA}) \text {, } \\
0.7158(\mathrm{~F} 1) \\
\text { Second } \\
\text { Dataset: } \\
83.82 \%(\mathrm{CA}) \text {, } \\
0.8274(\mathrm{~F} 1)\end{array}$ & $\begin{array}{l}\text { (lenco, } \\
\text { Gaetano, } \\
\text { Dupaquie } \\
\text { r, \& } \\
\text { Maurel, } \\
2017 \text { ) }\end{array}$ \\
\hline 9. & 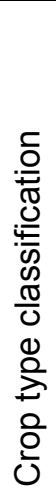 & $\begin{array}{l}\text { Classificatio } \\
\text { n of crops } \\
\text { wheat, } \\
\text { maize, } \\
\text { soybeans } \\
\text { sunflower } \\
\text { and sugar } \\
\text { beet }\end{array}$ & $\begin{array}{l}19 \text { multi-temporal } \\
\text { scenes acquired } \\
\text { by Landsat- } 8 \text { and } \\
\text { Sentinel-1A RS } \\
\text { satellites from a } \\
\text { test site in } \\
\text { Ukraine. }\end{array}$ & $\begin{array}{l}11 \text { classes: } \\
\text { water, forest, } \\
\text { grassland, } \\
\text { bare land, } \\
\text { wheat, maize, } \\
\text { rapeseed, } \\
\text { cereals, sugar } \\
\text { beet, } \\
\text { sunflowers and } \\
\text { soybeans. }\end{array}$ & $\begin{array}{c}\text { General } \\
\text { confusion } \\
\text { between maize } \\
\text { and soybeans }\end{array}$ & $\begin{array}{l}\text { Author- } \\
\text { defined } \\
\text { CNN }\end{array}$ & $\begin{array}{l}\text { Develop } \\
\text { ed by } \\
\text { the } \\
\text { authors }\end{array}$ & \begin{tabular}{|c|} 
Calibration, \\
multi-looking, \\
speckle \\
filtering $(3 \times 3$ \\
window with \\
Refined Lee \\
algorithm), \\
terrain \\
correction, \\
segmentation, \\
restoration of \\
missing data
\end{tabular} & N/A & Same & CA & $94.60 \%$ & $\begin{array}{l}\text { Multilayer } \\
\text { perceptron: } \\
92.7 \%, \\
\text { RF: } 88 \%\end{array}$ & $\begin{array}{l}\text { (Kussul, } \\
\text { Lavreniuk } \\
\text {, Skakun, } \\
\& \\
\text { Shelestov } \\
, \text { 2017) }\end{array}$ \\
\hline
\end{tabular}




\begin{tabular}{|c|c|c|c|c|c|c|c|c|c|c|c|c|c|c|}
\hline 10. & & $\begin{array}{l}\text { Classificatio } \\
\text { n of crops oil } \\
\text { radish, } \\
\text { barley, } \\
\text { seeded } \\
\text { grass, weed } \\
\text { and stump }\end{array}$ & $\begin{array}{l}36 \text { plots at Foulum } \\
\text { Research Center, } \\
\text { Denmark } \\
\text { containing oil } \\
\text { radish as a catch } \\
\text { crop and amounts } \\
\text { of barley, grass, } \\
\text { weed and stump. } \\
352 \text { patches in } \\
\text { total. }\end{array}$ & $\begin{array}{l}7 \text { classes: oil } \\
\text { radish, barley, } \\
\text { weed, stump, } \\
\text { soil, equipment } \\
\text { and unknown } \\
\text { (pixel of the } \\
\text { image) }\end{array}$ & $\begin{array}{l}\text { Coarse features } \\
\text { (radish leafs and } \\
\text { soil) were } \\
\text { predicted quite } \\
\text { well. Finer } \\
\text { features (barley, } \\
\text { grass or stump) } \\
\text { not so much. }\end{array}$ & $\begin{array}{c}\text { Adapted } \\
\text { version } \\
\text { of } \\
\text { VGG16 } \\
\text { CNN }\end{array}$ & $\begin{array}{l}\text { Develop } \\
\text { ed by } \\
\text { the } \\
\text { authors }\end{array}$ & \begin{tabular}{|} 
Resized to \\
$1600 \times 1600$ \\
pix. centered \\
on the sample \\
areas, division \\
into $400 \times 400$ \\
pix. patches
\end{tabular} & $\begin{array}{c}\text { Rotations } 0, \\
90,180 \text { and } \\
270 \\
\text { degrees, } \\
\text { flipped } \\
\text { diagonally } \\
\text { and same } \\
\text { set of } \\
\text { rotations }\end{array}$ & Same & CA, IOU & $\begin{array}{c}79 \% \\
\text { (CA), } \\
0.66 \text { (loU) }\end{array}$ & $N / A$ & $\begin{array}{l}\text { (Mortens } \\
\text { en, } \\
\text { Dyrmann, } \\
\text { Karstoft, } \\
\text { Jørgense } \\
\text { n, \& } \\
\text { Gislum, } \\
2016)\end{array}$ \\
\hline 11. & & $\begin{array}{l}\text { Crop type } \\
\text { classification } \\
\text { considering } \\
\text { time series }\end{array}$ & $\begin{array}{l}\text { A raster dataset of } \\
26 \text { SENTINEL 2A } \\
\text { images, acquired } \\
\text { between } 2015 \\
2016 \text { at Munich } \\
\text { Germany. } \\
\text { Shortwave infrared } \\
1 \text { and } 2 \text { bands } \\
\text { were selected. }\end{array}$ & $\begin{array}{l}19 \text { classes: } \\
\text { corn, meadow, } \\
\text { asparagus, } \\
\text { rape, hop, } \\
\text { summer oats, } \\
\text { winter spelt, } \\
\text { fallow, wheat, } \\
\text { barley, winter } \\
\text { rye, beans and } \\
\text { others }\end{array}$ & $\begin{array}{l}\text { Some classes } \\
\text { represent } \\
\text { distinct } \\
\text { cultivated crops, } \\
\text { others (such as } \\
\text { meadow, fallow, } \\
\text { triticale, wheat, } \\
\text { and rye) are } \\
\text { botanically } \\
\text { related. }\end{array}$ & $\begin{array}{l}\text { Three- } \\
\text { unit } \\
\text { LSTM }\end{array}$ & $\begin{array}{c}\text { TensorFI } \\
\text { ow }\end{array}$ & $\begin{array}{c}\text { Atmospherical } \\
\text { ly corrected }\end{array}$ & $\mathrm{N} / \mathrm{A}$ & Same & $\mathrm{CA}, \mathrm{F} 1$ & $\begin{array}{l}76.2 \% \\
(\mathrm{CA}) \\
0.558 \\
(\mathrm{~F} 1)\end{array}$ & $\begin{array}{c}\text { CNN: } 59.9 \% \\
(\mathrm{CA}), 0.236 \\
\text { (F1) } \\
\text { SVM: } 31.7 \\
(\mathrm{CA}), 84.8 \% \\
0.317(\mathrm{~F} 1)\end{array}$ & $\begin{array}{l}\text { (Rußwur } \\
\text { m \& } \\
\text { Körner, } \\
2017)\end{array}$ \\
\hline 12. & & $\begin{array}{l}\text { Crop type } \\
\text { classification } \\
\text { from UAV } \\
\text { imagery }\end{array}$ & $\begin{array}{l}\text { Aerial images of } \\
\text { experimental farm } \\
\text { fields issued from } \\
\text { a series of } \\
\text { experiments } \\
\text { conducted by the } \\
\text { Swiss } \\
\text { Confederation's } \\
\text { Agroscope } \\
\text { research center. }\end{array}$ & $\begin{array}{l}23 \text { classes: } 22 \\
\text { different crops } \\
\text { plus soil (pixel } \\
\text { of the image) }\end{array}$ & $\begin{array}{l}\text { Lin and Simplex } \\
\text { have very } \\
\text { similar } \\
\text { histograms }\end{array}$ & \begin{tabular}{|c|} 
CNN + \\
HistNN \\
(using \\
RGB \\
histogram \\
s)
\end{tabular} & Keras & $\begin{array}{c}\text { Image } \\
\text { segmentation }\end{array}$ & $\mathrm{N} / \mathrm{A}$ & Same & $\mathrm{F} 1$ & $\begin{array}{c}0.90 \\
\text { (experime } \\
\text { nt 0), } \\
0.73 \\
\text { (experime } \\
\text { nt 1) }\end{array}$ & $\begin{array}{c}\text { CNN: } 0.83 \\
\text { (experiment } \\
\text { 0), } 0.70 \\
\text { (experiment 1) } \\
\text { HistNN: } 0.86 \\
\text { (experiment } \\
\text { 0), } 0.71 \\
\text { (experiment 1) }\end{array}$ & $\begin{array}{l}\text { (Rebetez, } \\
\text { J., et al., } \\
2016)\end{array}$ \\
\hline 13.. & 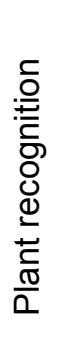 & $\begin{array}{l}\text { Recognize } 7 \\
\text { views of } \\
\text { different } \\
\text { plants: entire } \\
\text { plant, } \\
\text { branch, } \\
\text { flower, fruit, }\end{array}$ & $\begin{array}{l}\text { LifeCLEF } 2015 \\
\text { plant dataset, } \\
\text { which has } 91,759 \\
\text { images distributed } \\
\text { in } 13,887 \text { plant } \\
\text { observations. } \\
\text { Each observation } \\
\text { captures the }\end{array}$ & $\begin{array}{l}1,000 \text { classes: } \\
\text { Species that } \\
\text { include trees, } \\
\text { herbs, and } \\
\text { ferns, among } \\
\text { others. }\end{array}$ & $\begin{array}{c}\text { Images of } \\
\text { flowers and leaf } \\
\text { scans offer } \\
\text { higher accuracy } \\
\text { than the rest of } \\
\text { the views }\end{array}$ & $\begin{array}{c}\text { AlexNet } \\
\text { CNN }\end{array}$ & Caffe & $\mathrm{N} / \mathrm{A}$ & $\mathrm{N} / \mathrm{A}$ & Same & LC & $48.60 \%$ & $\begin{array}{l}20 \% \text { worse } \\
\text { than local } \\
\text { descriptors to } \\
\text { represent } \\
\text { images and } \\
\text { KNN, dense } \\
\text { SIFT and a } \\
\text { Gaussian }\end{array}$ & $\begin{array}{l}\text { (Reyes, } \\
\text { Caicedo, } \\
\& \\
\text { Camargo, } \\
2015)\end{array}$ \\
\hline
\end{tabular}




\begin{tabular}{|c|c|c|c|c|c|c|c|c|c|c|c|c|c|}
\hline & $\begin{array}{l}\text { leaf, stem } \\
\text { and scans }\end{array}$ & $\begin{array}{l}\text { appearance of the } \\
\text { plant from various } \\
\text { points of view: } \\
\text { entire plant, leaf } \\
\text { branch, fruit, stem } \\
\text { scan, flower. }\end{array}$ & & & & & & & & & & Mixture Model & \\
\hline 14. & $\begin{array}{l}\text { Root and } \\
\text { shoot feature } \\
\text { identification } \\
\text { and } \\
\text { localisation }\end{array}$ & $\begin{array}{l}\text { The first dataset } \\
\text { contains } 2,500 \\
\text { annotated images } \\
\text { of whole root } \\
\text { systems. The } \\
\text { second hand- } \\
\text { annotated } 1,664 \\
\text { images of wheat } \\
\text { plants, labeling } \\
\text { leaf tips, leaf } \\
\text { bases, ear tips, } \\
\text { and ear bases. }\end{array}$ & $\begin{array}{l}2 \text { classes: } \\
\text { Prediction if a } \\
\text { root tip is } \\
\text { present or not } \\
\text { (first dataset) } \\
5 \text { classes: Leaf } \\
\text { tips and bases, } \\
\text { ear tips and } \\
\text { bases, and } \\
\text { negative } \\
\text { (second } \\
\text { dataset) }\end{array}$ & $N / A$ & $\begin{array}{l}\text { Author- } \\
\text { defined } \\
\text { CNN }\end{array}$ & Caffe & \begin{tabular}{|} 
Image \\
cropping at \\
annotated \\
locations \\
$128 \times 128$ pix., \\
resized to \\
$64 \times 64$ for use \\
in the network
\end{tabular} & $\mathrm{N} / \mathrm{A}$ & Same & $\mathrm{CA}$ & $\begin{array}{c}98.4 \% \\
\text { (first } \\
\text { dataset) } \\
97.3 \% \\
\text { (second } \\
\text { dataset) }\end{array}$ & $\begin{array}{l}\text { Sparse coding } \\
\text { approach } \\
\text { using SIFT + } \\
\text { SVM: } 80-90 \%\end{array}$ & $\begin{array}{l}\text { (Pound, } \\
\text { M. P., et } \\
\text { al., 2016) }\end{array}$ \\
\hline 15. & $\begin{array}{l}\text { Recognize } \\
44 \text { different } \\
\text { plant species }\end{array}$ & $\begin{array}{l}\text { MalayaKew (MK) } \\
\text { Leaf Dataset } \\
\text { which consists of } \\
44 \text { classes, } \\
\text { collected at the } \\
\text { Royal Botanic } \\
\text { Gardens, Kew, } \\
\text { England. }\end{array}$ & $\begin{array}{l}44 \text { classes: } \\
\text { Species such } \\
\text { as acutissima, } \\
\text { macranthera, } \\
\text { rubra, robur f. } \\
\text { purpurascens } \\
\text { etc. }\end{array}$ & $\mathrm{N} / \mathrm{A}$ & $\begin{array}{l}\text { AlexNet } \\
\text { CNN }\end{array}$ & Caffe & $\begin{array}{l}\text { Foreground } \\
\text { pixels } \\
\text { extracted } \\
\text { using HSV } \\
\text { color space, } \\
\text { image } \\
\text { cropping } \\
\text { within leaf } \\
\text { area }\end{array}$ & $\begin{array}{c}\text { Rotation in } \\
7 \text { different } \\
\text { orientations }\end{array}$ & Same & $\mathrm{CA}$ & $99.60 \%$ & $\begin{array}{l}\text { SVM: } 95.1 \% \text {, } \\
\text { ANN: } 58 \%\end{array}$ & $\begin{array}{l}\text { (Lee, } \\
\text { Chan, } \\
\text { Wilkin, \& } \\
\text { Remagni } \\
\text { no, 2015) }\end{array}$ \\
\hline 16. & $\begin{array}{l}\text { Identify } \\
\text { plants from } \\
\text { leaf vein } \\
\text { patterns of } \\
\text { white, soya } \\
\text { and red } \\
\text { beans }\end{array}$ & $\begin{array}{l}866 \text { leaf images } \\
\text { provided by INTA } \\
\text { Argentina. Dataset } \\
\text { divided into three } \\
\text { classes: } 422 \\
\text { images } \\
\text { correspond to } \\
\text { soybean leaves, } \\
272 \text { to red bean } \\
\text { leaves and } 172 \text { to } \\
\text { white bean leaves. }\end{array}$ & $\begin{array}{l}3 \text { classes: } \\
\text { Legume } \\
\text { species white } \\
\text { bean, } \\
\text { red bean and } \\
\text { soybean }\end{array}$ & $\begin{array}{l}\text { At soybean, } \\
\text { informative } \\
\text { regions are in } \\
\text { the central vein. } \\
\text { For white and } \\
\text { red bean, outer } \\
\text { and smaller } \\
\text { veins are also } \\
\text { relevant. }\end{array}$ & $\begin{array}{l}\text { Author- } \\
\text { defined } \\
\text { CNN }\end{array}$ & Pylearn2 & $\begin{array}{c}\text { Vein } \\
\text { segmentation, } \\
\text { central patch } \\
\text { extraction }\end{array}$ & $\mathrm{N} / \mathrm{A}$ & Same & $\mathrm{CA}$ & $96.90 \%$ & $\begin{array}{l}\text { Penalized } \\
\text { Discriminant } \\
\text { Analysis } \\
\text { (PDA): } 95.1 \% \\
\text { SVM and RF } \\
\text { slightly worse }\end{array}$ & $\begin{array}{l}\text { (Grinblat, } \\
\text { Uzal, } \\
\text { Larese, \& } \\
\text { Granitto, } \\
2016)\end{array}$ \\
\hline
\end{tabular}




\begin{tabular}{|c|c|c|c|c|c|c|c|c|c|c|c|c|c|c|}
\hline 17. & & $\begin{array}{l}\text { Classify } \\
\text { phenological } \\
\text { stages of } \\
\text { several } \\
\text { types of } \\
\text { plants purely } \\
\text { based on the } \\
\text { visual data }\end{array}$ & $\begin{array}{l}\text { Dataset collected } \\
\text { through TARBIL } \\
\text { Agro-informatics } \\
\text { Research Center } \\
\text { of ITU, for which } \\
\text { over a thousand } \\
\text { agrostations are } \\
\text { placed throughout } \\
\text { Turkey. Different } \\
\text { images of various } \\
\text { plants, at different } \\
\text { phenological } \\
\text { stages. }\end{array}$ & $\begin{array}{l}9 \text { classes: } \\
\text { Different } \\
\text { growth stages } \\
\text { of plants, } \\
\text { starting from } \\
\text { plowing to } \\
\text { cropping, for } \\
\text { the plants } \\
\text { wheat, barley, } \\
\text { lentil, cotton, } \\
\text { pepper and } \\
\text { corn. (image } \\
\text { segment) }\end{array}$ & $\begin{array}{c}\text { Appearances } \\
\text { change very } \\
\text { gradually and it } \\
\text { is challenging to } \\
\text { distinguish } \\
\text { images falling } \\
\text { into the growing } \\
\text { durations that } \\
\text { are in the middle } \\
\text { of two } \\
\text { successive } \\
\text { stages. Some } \\
\text { plants from } \\
\text { different classes } \\
\text { have } \\
\text { similar color and } \\
\text { texture } \\
\text { distributions }\end{array}$ & $\begin{array}{c}\text { AlexNet } \\
\text { CNN }\end{array}$ & $\begin{array}{l}\text { Develop } \\
\text { ed by } \\
\text { the } \\
\text { authors }\end{array}$ & $\begin{array}{c}\text { Image } \\
\text { segmentation }\end{array}$ & $\begin{array}{l}\text { Images are } \\
\text { divided into } \\
\text { large } \\
\text { patches and } \\
\text { features are } \\
\text { extracted } \\
\text { for each } \\
\text { patch. } \\
227 \times 227 \\
\text { pix. patches } \\
\text { are carved } \\
\text { from the } \\
\text { original } \\
\text { images }\end{array}$ & Same & $\mathrm{CA}, \mathrm{F} 1$ & $\begin{array}{c}73.76- \\
87.14 \\
(\mathrm{CA}), \\
0.7417- \\
0.8728 \\
(\mathrm{~F} 1)\end{array}$ & $\begin{array}{l}\text { Hand crafted } \\
\text { feature } \\
\text { descriptors } \\
\text { (GLCM and } \\
\text { HOG) through } \\
\text { a Naïve- } \\
\text { Bayes } \\
\text { classifier: } \\
68.97-82.41 \\
(\mathrm{CA}), 0.6931 \\
-0.8226(\mathrm{~F} 1)\end{array}$ & $\begin{array}{l}\text { (Yalcin, } \\
2017 \text { ) }\end{array}$ \\
\hline 18. & 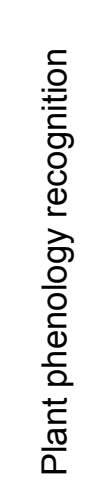 & $\begin{array}{l}\text { Classify the } \\
\text { phenotyping } \\
\text { of } \\
\text { Arabidopsis } \\
\text { in four } \\
\text { accessions }\end{array}$ & $\begin{array}{l}\text { Dataset composed } \\
\text { of sequences of } \\
\text { images captured } \\
\text { from the plants in } \\
\text { different days } \\
\text { while they grow, } \\
\text { successive top- } \\
\text { view images of } \\
\text { different } \\
\text { accessions of } \\
\text { Arabidopsis } \\
\text { thaliana. }\end{array}$ & $\begin{array}{l}4 \text { classes: } 4 \\
\text { different } \\
\text { accessions of } \\
\text { Arabidopsis: } \\
\text { Genotype } \\
\text { states SF-2, } \\
\text { CVI, Landsberg } \\
\text { (Ler) and } \\
\text { Columbia (Col) }\end{array}$ & $\begin{array}{l}\text { Plants change in } \\
\text { size rapidly } \\
\text { during their } \\
\text { growth, the } \\
\text { decomposed } \\
\text { images from the } \\
\text { plant sequences } \\
\text { are not } \\
\text { sufficiently } \\
\text { consistent }\end{array}$ & $\begin{array}{l}\text { CNN+ } \\
\text { LSTM }\end{array}$ & $\begin{array}{l}\text { Keras/ } \\
\text { Theano }\end{array}$ & $\begin{array}{l}\text { Camera } \\
\text { distortion } \\
\text { removal, color } \\
\text { correction, } \\
\text { temporal } \\
\text { matching, } \\
\text { plant } \\
\text { segmentation } \\
\text { through the } \\
\text { GrabCut } \\
\text { algorithm }\end{array}$ & $\begin{array}{c}\text { Image } \\
\text { rotations by } \\
90,180 \text { and } \\
270 \\
\text { degrees } \\
\text { around its } \\
\text { center }\end{array}$ & Same & CA & $93 \%$ & $\begin{array}{l}\text { Hand crafted } \\
\text { feature } \\
\text { descriptors + } \\
\text { LSTM: } 68 \% \\
\text { CNN: } 76.8 \%\end{array}$ & $\begin{array}{l}\text { (Namin, } \\
\text { Esmaeilz } \\
\text { adeh, } \\
\text { Najafi, } \\
\text { Brown, \& } \\
\text { Borevitz, } \\
2017)\end{array}$ \\
\hline 19. & 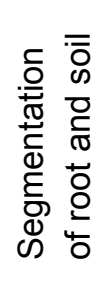 & $\begin{array}{l}\text { Identify roots } \\
\text { from soils }\end{array}$ & $\begin{array}{l}\text { Soil images } \\
\text { coming from X-ray } \\
\text { tomography. }\end{array}$ & $\begin{array}{l}2 \text { classes: Root } \\
\text { or soil (pixel of } \\
\text { the image) }\end{array}$ & $\begin{array}{c}\text { Soil/root } \\
\text { contrast is } \\
\text { sometimes very } \\
\text { low }\end{array}$ & $\begin{array}{l}\text { Author- } \\
\text { defined } \\
\text { CNN } \\
\text { with } \\
\text { SVM for } \\
\text { classific } \\
\text { ation }\end{array}$ & $\begin{array}{c}\text { MatCon } \\
\text { vNet }\end{array}$ & $\begin{array}{c}\text { Image } \\
\text { segmentation }\end{array}$ & $\begin{array}{c}\text { Simulated } \\
\text { roots added } \\
\text { to soil } \\
\text { images }\end{array}$ & Same & QM & $\begin{array}{c}0.23 \\
\text { (simulati } \\
\text { on) } \\
0.57 \\
\text { (real } \\
\text { roots) }\end{array}$ & N/A & $\begin{array}{l}\text { (Douarre, } \\
\text { Schielein, } \\
\text { Frindel, } \\
\text { Gerth, \& } \\
\text { Roussea } \\
\text { u, 2016) }\end{array}$ \\
\hline
\end{tabular}




\begin{tabular}{|c|c|c|c|c|c|c|c|c|c|c|c|c|c|c|}
\hline 20. & & $\begin{array}{l}\text { Estimate } \\
\text { corn yield of } \\
\text { county level } \\
\text { in U.S. }\end{array}$ & $\begin{array}{l}\text { Corn yields from } \\
2001 \text { to } 2010 \text { in } \\
\text { Illinois U.S., } \\
\text { downloaded from } \\
\text { Climate Research } \\
\text { Unit (CRU), plus } \\
\text { MODIS Enhanced } \\
\text { Vegetation Index. }\end{array}$ & $\begin{array}{l}\text { Crop yield } \\
\text { index (scalar } \\
\text { value) }\end{array}$ & $\mathrm{N} / \mathrm{A}$ & $\begin{array}{l}\text { Author- } \\
\text { defined } \\
\text { CNN }\end{array}$ & Caffe & $\begin{array}{c}\text { Enhanced } \\
\text { Vegetation } \\
\text { Index (EVI), } \\
\text { hard threshold } \\
\text { algorithm, } \\
\text { Wavelet } \\
\text { transformation } \\
\text { for detecting } \\
\text { crop } \\
\text { phenology }\end{array}$ & N/A & Same & RMSE & 6.298 & $\begin{array}{l}\text { Support } \\
\text { Vector } \\
\text { Regression } \\
\text { (SVR): } 8.204\end{array}$ & $\begin{array}{l}\text { (Kuwata } \\
\& \\
\text { Shibasaki } \\
\text {, 2015) }\end{array}$ \\
\hline 21. & 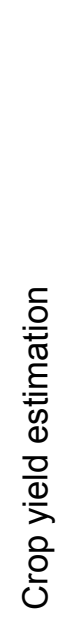 & $\begin{array}{l}\text { Mapping } \\
\text { winter } \\
\text { vegetation } \\
\text { quality } \\
\text { coverage } \\
\text { considering } \\
\text { time series }\end{array}$ & $\begin{array}{l}\text { Sentinel- } 1 \text { dataset } \\
\text { including } 13 \\
\text { acquisitions in } \\
\text { TOPS mode from } \\
\text { October } 2016 \text { to } \\
\text { February } 2017 \text {, } \\
\text { with a temporal } \\
\text { baseline of } 12 \\
\text { days. Dual- } \\
\text { polarization } \\
(\mathrm{VV}+\mathrm{VH}) \text { data in } \\
26 \text { images. }\end{array}$ & $\begin{array}{l}5 \text { classes: } \\
\text { Estimations of } \\
\text { the quality of } \\
\text { vegetative } \\
\text { development } \\
\text { as bare soil, } \\
\text { very low, low, } \\
\text { average, high }\end{array}$ & $\begin{array}{l}\text { "Low" class } \\
\text { intersects the } \\
\text { temporal profiles } \\
\text { of all the other } \\
\text { classes multiple } \\
\text { times. A } \\
\text { misclassification } \\
\text { rate exists } \\
\text { between the } \\
\text { "low" and "bare } \\
\text { soil" classes }\end{array}$ & $\begin{array}{l}\text { Five-unit } \\
\text { LSTM, } \\
\text { Gated } \\
\text { Recurre } \\
\text { nt Unit } \\
\text { (GRU) }\end{array}$ & $\begin{array}{l}\text { Keras/ } \\
\text { Theano }\end{array}$ & \begin{tabular}{|c|} 
Intensity \\
image gen., \\
radiometrical \\
calibration, \\
temporal \\
filtering for \\
noise \\
reduction, \\
orthorectificati \\
on into map \\
coordinates, \\
transformed to \\
logarithm \\
scale, \\
normalized
\end{tabular} & N/A & Same & CA, F1 & $\begin{array}{c}99.05 \% \\
(\mathrm{CA}), \\
0.99 \text { (F1) }\end{array}$ & $\begin{array}{l}\text { RF and SVM } \\
\text { (best of both): } \\
91.77 \%(\mathrm{CA}) \text {, } \\
0.9179(\mathrm{~F} 1)\end{array}$ & $\begin{array}{l}\text { (Minh, et } \\
\text { al., 2017) }\end{array}$ \\
\hline 22. & 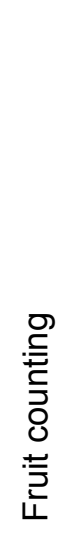 & $\begin{array}{l}\text { Predict } \\
\text { number of } \\
\text { tomatoes in } \\
\text { the images }\end{array}$ & $\begin{array}{l}24,000 \text { synthetic } \\
\text { images produced } \\
\text { by the authors. }\end{array}$ & $\begin{array}{l}\text { Estimated } \\
\text { number of } \\
\text { tomato fruits } \\
\text { (scalar value) }\end{array}$ & $\mathrm{N} / \mathrm{A}$ & $\begin{array}{l}\text { Modified } \\
\text { Inceptio } \\
n- \\
\text { ResNet } \\
\text { CNN }\end{array}$ & $\begin{array}{c}\text { TensorFI } \\
\text { ow }\end{array}$ & $\begin{array}{c}\text { Blurred } \\
\text { synthetic } \\
\text { images by a } \\
\text { Gaussian filter }\end{array}$ & $\begin{array}{l}\text { Generated } \\
\text { synthetic } \\
128 \times 128 \\
\text { pix. images } \\
\text { to train the } \\
\text { network, } \\
\text { colored } \\
\text { circles to } \\
\text { simulate } \\
\text { background } \\
\text { and tomato } \\
\text { plant/crops. }\end{array}$ & $\begin{array}{l}\text { Trained } \\
\text { entirely on } \\
\text { synthetic } \\
\text { data and } \\
\text { tested on } \\
\text { real data }\end{array}$ & $\begin{array}{l}\text { RFC, } \\
\text { RMSE }\end{array}$ & $\begin{array}{c}91 \% \\
\text { (RFC) } \\
1.16 \\
\text { (RMSE) } \\
\text { on real } \\
\text { images, } \\
93 \% \\
\text { (RFC) } \\
2.52 \\
\text { (RMSE) } \\
\text { on } \\
\text { synthetic } \\
\text { images }\end{array}$ & $\begin{array}{l}\text { ABT: } 66.16 \% \\
\text { (RFC), } 13.56 \\
\text { (RMSE) }\end{array}$ & $\begin{array}{l}\text { (Rahnem } \\
\text { oonfar \& } \\
\text { Sheppard } \\
\text {, 2017) }\end{array}$ \\
\hline
\end{tabular}




\begin{tabular}{|c|c|c|c|c|c|c|c|c|c|c|c|c|c|c|}
\hline 23. & & $\begin{array}{l}\text { Map from } \\
\text { input images } \\
\text { of apples } \\
\text { and oranges } \\
\text { to total fruit } \\
\text { counts }\end{array}$ & $\begin{array}{l}711280 \times 960 \\
\text { orange images } \\
\text { (day time) and } 21 \\
1920 \times 1200 \text { apple } \\
\text { images (night } \\
\text { time). }\end{array}$ & $\begin{array}{l}\text { Number of } \\
\text { orange or } \\
\text { apple fruits } \\
\text { (scalar value) }\end{array}$ & $\begin{array}{l}\text { High variation in } \\
\text { CA. For orange, } \\
\text { dataset has high } \\
\text { occlusion, depth } \\
\text { variation, and } \\
\text { uncontrolled } \\
\text { illumination. For } \\
\text { apples, data set } \\
\text { has high color } \\
\text { similarity } \\
\text { between } \\
\text { fruit/foliage }\end{array}$ & $\begin{array}{l}\text { CNN } \\
\text { (blob } \\
\text { detection } \\
\text { and } \\
\text { counting) } \\
+ \text { Linear } \\
\text { Regressi } \\
\quad \text { on }\end{array}$ & Caffe & \begin{tabular}{|} 
Image \\
segmentation \\
for easier data \\
annotation by \\
users, \\
creation of \\
bounding \\
boxes around \\
image blobs
\end{tabular} & $\begin{array}{l}\text { Training set } \\
\text { partitioned } \\
\text { into } 100 \\
\text { randomly } \\
\text { cropped } \\
\text { and flipped } \\
320 \times 240 \\
\text { pix. sub- } \\
\text { images }\end{array}$ & $\begin{array}{l}\text { Same (but } \\
\text { different } \\
\text { trees used } \\
\text { in training } \\
\text { and testing) }\end{array}$ & $\begin{array}{l}\text { RFC, } \\
\text { L2 }\end{array}$ & $\begin{array}{c}0.968 \\
\text { (RFC), } \\
13.8(\text { L2) } \\
\text { for } \\
\text { oranges } \\
0.913 \\
\text { (RFC), } \\
10.5 \text { (L2) } \\
\text { for apples }\end{array}$ & $\begin{array}{l}\text { Best texture- } \\
\text { based } \\
\text { regression } \\
\text { model: } 0.682 \\
(\mathrm{RFC})\end{array}$ & $\begin{array}{l}\text { (Chen, et } \\
\text { al., 2017) }\end{array}$ \\
\hline 24. & & $\begin{array}{l}\text { Fruit } \\
\text { detection } \\
\text { in orchards, } \\
\text { including } \\
\text { mangoes, } \\
\text { almonds and } \\
\text { apples }\end{array}$ & $\begin{array}{l}\text { Images of three } \\
\text { fruit varieties: } \\
\text { apples }(726), \\
\text { almonds }(385) \text { and } \\
\text { mangoes }(1,154), \\
\text { captured at } \\
\text { orchards in } \\
\text { Victoria and } \\
\text { Queensland, } \\
\text { Australia. }\end{array}$ & $\begin{array}{l}\text { Sections of } \\
\text { apples, } \\
\text { almonds and } \\
\text { mangoes at the } \\
\text { image } \\
\text { (bounding box) }\end{array}$ & $\begin{array}{l}\text { Within class } \\
\text { variations due to } \\
\text { distance to fruit } \\
\text { illumination, fruit } \\
\text { clustering, and } \\
\text { camera view- } \\
\text { point. Almonds } \\
\text { similar in color } \\
\text { and texture to } \\
\text { the foliage }\end{array}$ & $\begin{array}{l}\text { Faster } \\
\text { Region- } \\
\text { based } \\
\text { CNN } \\
\text { with } \\
\text { VGG16 } \\
\text { model }\end{array}$ & Caffe & $\begin{array}{c}\text { Image } \\
\text { segmentation } \\
\text { for easier data } \\
\text { annotation }\end{array}$ & $\begin{array}{l}\text { Flip, scale, } \\
\text { flip-scale } \\
\text { and the } \\
\text { PCA } \\
\text { augmentati } \\
\text { on } \\
\text { technique } \\
\text { presented } \\
\text { in AlexNet }\end{array}$ & Same & $\begin{array}{c}\text { F1-IoU } \\
(20)\end{array}$ & $\begin{array}{c}0.904 \\
\text { (apples) } \\
0.908 \\
\text { (mango) } \\
0.775 \\
\text { (almonds) }\end{array}$ & $\begin{array}{l}\text { ZF network: } \\
0.892 \\
\text { (apples) } \\
0.876 \\
\text { (mango) } \\
0.726 \\
\text { (almonds) }\end{array}$ & $\begin{array}{l}\text { (Bargoti \& } \\
\text { Underwo } \\
\text { od, 2016) }\end{array}$ \\
\hline 25. & & $\begin{array}{l}\text { Detection of } \\
\text { sweet } \\
\text { pepper and } \\
\text { rock melon } \\
\text { fruits }\end{array}$ & $\begin{array}{l}122 \text { images } \\
\text { obtained from two } \\
\text { modalities: color } \\
\text { (RGB) and Near- } \\
\text { Infrared (NIR). }\end{array}$ & $\begin{array}{l}\text { Sections of } \\
\text { sweet red } \\
\text { peppers and } \\
\text { rock melons on } \\
\text { the image } \\
\text { (bounding box) }\end{array}$ & $\begin{array}{l}\text { Variations to } \\
\text { camera setup, } \\
\text { time and } \\
\text { locations of data } \\
\text { acquisition. } \\
\text { Time for data } \\
\text { collection is day } \\
\text { and night, sites } \\
\text { are different. } \\
\text { Varied fruit } \\
\text { ripeness. }\end{array}$ & $\begin{array}{l}\text { Faster } \\
\text { Region- } \\
\text { based } \\
\text { CNN } \\
\text { with } \\
\text { VGG16 } \\
\text { model }\end{array}$ & Caffe & \begin{tabular}{|} 
Early/late \\
fusion \\
techniques for \\
combining the \\
classification \\
info from color \\
and NIR \\
imagery, \\
bounding box \\
segmentation, \\
pairwise loU
\end{tabular} & $\mathrm{N} / \mathrm{A}$ & $\begin{array}{c}\text { Same } \\
\text { (authors } \\
\text { demonstrat } \\
\text { e by using a } \\
\text { small } \\
\text { dataset that } \\
\text { the model } \\
\text { can } \\
\text { generalize) }\end{array}$ & $\begin{array}{c}\text { F1-loU } \\
(40)\end{array}$ & 0.838 & $\begin{array}{l}\text { Conditional } \\
\text { Random Field } \\
\text { to model color } \\
\text { and visual } \\
\text { texture } \\
\text { features: } \\
0.807\end{array}$ & $\begin{array}{l}\text { (Sa, et } \\
\text { al., 2016) }\end{array}$ \\
\hline 26. & 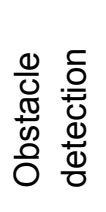 & $\begin{array}{l}\text { Identify ISO } \\
\text { barrel- } \\
\text { shaped } \\
\text { obstacles in }\end{array}$ & $\begin{array}{l}437 \text { images from } \\
\text { authors' } \\
\text { experiments and } \\
\text { recordings, } 1,925 \\
\text { positive and }\end{array}$ & $\begin{array}{l}\text { Identify if a } \\
\text { barrel-shaped } \\
\text { object is } \\
\text { present in the } \\
\text { image }\end{array}$ & $\mathrm{N} / \mathrm{A}$ & $\begin{array}{l}\text { AlexNet } \\
\text { CNN }\end{array}$ & Caffe & \begin{tabular}{|} 
Resized to \\
$114 \times 114$ pix., \\
bounding \\
boxes of the \\
object created
\end{tabular} & $\begin{array}{c}\text { Various } \\
\text { rotations at } \\
13 \text { scales, } \\
\text { intensity of } \\
\text { the object }\end{array}$ & $\begin{array}{l}\text { Testing in } \\
\text { different } \\
\text { fields (row } \\
\text { crops, grass } \\
\text { mowing), }\end{array}$ & $\begin{array}{c}\text { CA-IoU } \\
(50)\end{array}$ & $\begin{array}{l}99.9 \% \text { in } \\
\text { row } \\
\text { crops } \\
\text { and } \\
90.8 \% \text { in }\end{array}$ & $\mathrm{N} / \mathrm{A}$ & $\begin{array}{l}\text { (Steen, } \\
\text { Christians } \\
\text { en, } \\
\text { Karstoft, } \\
\text { \& }\end{array}$ \\
\hline
\end{tabular}




\begin{tabular}{|c|c|c|c|c|c|c|c|c|c|c|c|c|c|c|}
\hline & & $\begin{array}{l}\text { row crops } \\
\text { and grass } \\
\text { mowing }\end{array}$ & $\begin{array}{l}11,550 \text { negative } \\
\text { samples. }\end{array}$ & (bounding box) & & & & & adapted & $\begin{array}{l}\text { containing } \\
\text { other } \\
\text { obstacles } \\
\text { (people and } \\
\text { animals) }\end{array}$ & & $\begin{array}{l}\text { grass } \\
\text { mowing }\end{array}$ & & $\begin{array}{l}\text { Jørgense } \\
n, 2016)\end{array}$ \\
\hline 27. & & $\begin{array}{l}\text { Detect } \\
\text { obstacles } \\
\text { that are } \\
\text { distant, } \\
\text { heavily } \\
\text { occluded } \\
\text { and } \\
\text { unknown }\end{array}$ & $\begin{array}{l}\text { Background data } \\
\text { of } 48 \text { images and } \\
\text { test data of } 48 \\
\text { images from } \\
\text { annotations of } \\
\text { humans, houses, } \\
\text { barrels, wells and } \\
\text { mannequins. }\end{array}$ & $\begin{array}{l}\text { Classify each } \\
\text { pixel as either } \\
\text { foreground } \\
\text { (contains a } \\
\text { human) or } \\
\text { background } \\
\text { (anomaly } \\
\text { detection) }\end{array}$ & $\mathrm{N} / \mathrm{A}$ & $\begin{array}{l}\text { AlexNet } \\
\text { and } \\
\text { VGG } \\
\text { CNNs }\end{array}$ & Caffe & $\begin{array}{c}\text { Image } \\
\text { cropping, } \\
\text { resized by a } \\
\text { factor of } 0.75\end{array}$ & $\mathrm{~N} / \mathrm{A}$ & Same & $\begin{array}{c}\text { F1-loU } \\
(50)\end{array}$ & 0.72 & $\begin{array}{l}\text { Local de- } \\
\text { correlated } \\
\text { channel } \\
\text { features: } \\
0.113\end{array}$ & $\begin{array}{l}\text { (Christian } \\
\text { sen, } \\
\text { Nielsen, } \\
\text { Steen, } \\
\text { Jørgense } \\
\text { n, \& } \\
\text { Karstoft, } \\
2016)\end{array}$ \\
\hline 28. & \multirow{3}{*}{ 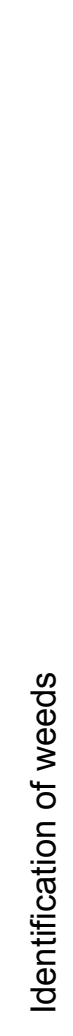 } & $\begin{array}{l}\text { Classify } 91 \\
\text { weed seed } \\
\text { types }\end{array}$ & $\begin{array}{l}\text { Dataset of } 3,980 \\
\text { images containing } \\
91 \text { types of weed } \\
\text { seeds. }\end{array}$ & $\begin{array}{l}91 \text { classes: } \\
\text { Different } \\
\text { common } \\
\text { weeds found in } \\
\text { agricultural } \\
\text { fields }\end{array}$ & $\begin{array}{c}\text { Similarity } \\
\text { between some } \\
\text { classes is very } \\
\text { high (only slight } \\
\text { differences in } \\
\text { shape, texture, } \\
\text { and color) }\end{array}$ & $\begin{array}{c}\text { PCANet } \\
+ \text { LMC } \\
\text { classifier } \\
\mathrm{s}\end{array}$ & $\begin{array}{l}\text { Develop } \\
\text { ed by } \\
\text { the } \\
\text { authors }\end{array}$ & $\begin{array}{l}\text { Image filter } \\
\text { extraction } \\
\text { through PCA } \\
\text { filters bank, } \\
\text { binarization } \\
\text { and } \\
\text { histograms' } \\
\text { counting }\end{array}$ & $\mathrm{N} / \mathrm{A}$ & \begin{tabular}{|} 
Same (also \\
scaling for a \\
certain \\
range \\
translation \\
distance \\
and rotation \\
angle
\end{tabular} & $\mathrm{CA}$ & $90.96 \%$ & $\begin{array}{l}\text { Manual } \\
\text { feature } \\
\text { extraction } \\
\text { techniques + } \\
\text { LMC } \\
\text { classifiers: } \\
64.80 \%\end{array}$ & $\begin{array}{l}\text { (Xinshao } \\
\text { \& Cheng, } \\
2015)\end{array}$ \\
\hline 29. & & $\begin{array}{l}\text { Classify } \\
\text { weed from } \\
\text { crop species } \\
\text { based on } 22 \\
\text { different } \\
\text { species in } \\
\text { total. }\end{array}$ & $\begin{array}{l}\text { Dataset of } 10,413 \\
\text { images, taken } \\
\text { mainly from } \mathrm{BBCH} \\
12-16 \text { containing } \\
22 \text { weed and crop } \\
\text { species at early } \\
\text { growth stages. }\end{array}$ & $\begin{array}{l}22 \text { classes: } \\
\text { Different } \\
\text { species of } \\
\text { weeds and } \\
\text { crops at early } \\
\text { growth stages } \\
\text { e.g. } \\
\text { chamomile, } \\
\text { knotweed, } \\
\text { cranesbill, } \\
\text { chickweed and } \\
\text { veronica }\end{array}$ & $\begin{array}{l}\text { Variations with } \\
\text { respect to } \\
\text { lighting, } \\
\text { resolution, and } \\
\text { soil type. Some } \\
\text { species } \\
\text { (Veronica, Field } \\
\text { Pancy) were } \\
\text { very similar and } \\
\text { difficult to } \\
\text { classify }\end{array}$ & $\begin{array}{c}\text { Variation } \\
\text { of } \\
\text { VGG16 }\end{array}$ & $\begin{array}{l}\text { Theano- } \\
\text { based } \\
\text { Lasagne } \\
\text { library } \\
\text { for } \\
\text { Python }\end{array}$ & $\begin{array}{c}\text { Green } \\
\text { segmentation } \\
\text { to detect } \\
\text { green pixels, } \\
\text { non-green } \\
\text { pixels } \\
\text { removal, } \\
\text { padding } \\
\text { added to } \\
\text { make images } \\
\text { square, } \\
\text { resized to } \\
128 \times 128 \text { pix. }\end{array}$ & $\begin{array}{c}\text { Image } \\
\text { mirroring } \\
\text { and rotation } \\
\text { in } 90 \\
\text { degree } \\
\text { increments }\end{array}$ & Same & $\mathrm{CA}$ & $86.2 \%$ & $\begin{array}{l}\text { Local shape } \\
\text { and color } \\
\text { features: } \\
42.5 \% \text { and } \\
12.2 \% \\
\text { respectively }\end{array}$ & $\begin{array}{l}\text { (Dyrmann } \\
\text {, Karstoft, } \\
\text { \& Midtiby, } \\
2016 \text { ) }\end{array}$ \\
\hline 30. & & $\begin{array}{l}\text { Identify } \\
\text { thistle in }\end{array}$ & $\begin{array}{l}4,500 \text { images from } \\
10,20,30, \text { and } \\
50 \mathrm{~m} \text { of altitude }\end{array}$ & $\begin{array}{l}2 \text { classes: } \\
\text { Whether the } \\
\text { image contains }\end{array}$ & $\begin{array}{c}\text { Small variations } \\
\text { in some images } \\
\text { depending on }\end{array}$ & $\begin{array}{l}\text { DenseN } \\
\text { et CNN }\end{array}$ & Caffe & $\begin{array}{l}\text { Image } \\
\text { cropping }\end{array}$ & $\begin{array}{l}\text { Random flip } \\
\text { both } \\
\text { horizontally }\end{array}$ & $\begin{array}{c}\text { Same (extra } \\
\text { tests for the } \\
\text { case of }\end{array}$ & CA & $97 \%$ & $\begin{array}{l}\text { Color feature- } \\
\text { based Thistle- } \\
\text { Tool: } 95 \%\end{array}$ & $\begin{array}{l}\text { (Sørense } \\
\mathrm{n}, \\
\text { Rasmuss }\end{array}$ \\
\hline
\end{tabular}




\begin{tabular}{|c|c|c|c|c|c|c|c|c|c|c|c|c|c|}
\hline & $\begin{array}{l}\text { winter wheat } \\
\text { and spring } \\
\text { barley } \\
\text { images }\end{array}$ & $\begin{array}{l}\text { captured by a } \\
\text { Canon PowerShot } \\
\text { G15 camera. }\end{array}$ & $\begin{array}{l}\text { thistle in winter } \\
\text { wheat or not } \\
\text { (Heatmap of } \\
\text { classes is } \\
\text { generated at } \\
\text { the output) }\end{array}$ & $\begin{array}{l}\text { the percentage } \\
\text { of thistles they } \\
\text { contain }\end{array}$ & & & & $\begin{array}{c}\text { and } \\
\text { vertically, } \\
\text { random } \\
\text { transposing }\end{array}$ & $\begin{array}{l}\text { winter } \\
\text { barley) }\end{array}$ & & & & $\begin{array}{l}\text { en, } \\
\text { Nielsen, } \\
\& \\
\text { Jørgense } \\
\text { n, 2017) }\end{array}$ \\
\hline 31. & $\begin{array}{l}\text { Weed } \\
\text { segmentatio } \\
\text { n for robotic } \\
\text { platforms }\end{array}$ & $\begin{array}{l}\text { Crop/Weed Field } \\
\text { Image Dataset } \\
\text { (CW-FID), consists } \\
\text { of } 20 \text { training and } \\
40 \text { testing images. } \\
\text { A dataset of } 60 \\
\text { top-down field } \\
\text { images of a } \\
\text { common culture } \\
\text { (organic carrots) } \\
\text { with the presence } \\
\text { of intra-row and } \\
\text { close-to-crop } \\
\text { weeds. }\end{array}$ & $\begin{array}{l}2 \text { classes: } \\
\text { carrot plants } \\
\text { and weeds } \\
\text { (image region) }\end{array}$ & N/A & $\begin{array}{c}\text { Adapted } \\
\text { version of } \\
\text { Inception- } \\
\text { v3 + } \\
\text { lightweigh } \\
\text { t DCNN + } \\
\text { set of K } \\
\text { lightweigh } \\
\text { t models } \\
\text { as a } \\
\text { mixture } \\
\text { model } \\
\text { (MixDCN } \\
N \text { ) }\end{array}$ & $\begin{array}{c}\text { TensorFI } \\
\text { ow }\end{array}$ & $\begin{array}{c}\text { Image up- } \\
\text { sampling to } \\
299 \times 299 \text { pix., } \\
\text { NDVI-based } \\
\text { vegetation } \\
\text { masks, } \\
\text { extracting } \\
\text { regions based } \\
\text { on a sliding } \\
\text { window on the } \\
\text { color image }\end{array}$ & $\mathrm{N} / \mathrm{A}$ & $\begin{array}{c}\text { Same } \\
\text { (different } \\
\text { carrot fields } \\
\text { used for } \\
\text { testing) }\end{array}$ & $\mathrm{CA}$ & $93.90 \%$ & $\begin{array}{l}\text { Feature } \\
\text { extraction } \\
\text { (shape and } \\
\text { statistical } \\
\text { features) and } \\
\text { RF classifier: } \\
85.9 \%\end{array}$ & $\begin{array}{l}\text { (McCool, } \\
\text { Perez, \& } \\
\text { Upcroft, } \\
\text { 2017) }\end{array}$ \\
\hline 32. & $\begin{array}{l}\text { Automating } \\
\text { weed } \\
\text { detection in } \\
\text { color images } \\
\text { despite } \\
\text { heavy leaf } \\
\text { occlusion }\end{array}$ & $\begin{array}{l}1,427 \text { images from } \\
\text { winter wheat } \\
\text { fields, of which } \\
18,541 \text { weeds } \\
\text { have been } \\
\text { annotated, } \\
\text { collected using a } \\
\text { camera mounted } \\
\text { on an all-terrain } \\
\text { vehicle. }\end{array}$ & $\begin{array}{l}\text { Detect single } \\
\text { weed instances } \\
\text { in images of } \\
\text { cereal fields } \\
\text { (bounding box). } \\
\text { A coverage } \\
\text { map is } \\
\text { produced. }\end{array}$ & $\begin{array}{l}\text { Large parts of } \\
\text { the weeds } \\
\text { overlap with } \\
\text { wheat plants }\end{array}$ & $\begin{array}{l}\text { Based on } \\
\text { DetectNet } \\
\text { CNN } \\
\text { (which is } \\
\text { based on } \\
\text { GoogLeN } \\
\text { et CNN) }\end{array}$ & $\begin{array}{l}\text { Develop } \\
\text { ed by } \\
\text { the } \\
\text { authors }\end{array}$ & $\begin{array}{l}\text { Resized to } \\
1224 \times 1024 \\
\text { pix. }\end{array}$ & $N / A$ & $\begin{array}{l}\text { Different } \\
\text { field used } \\
\text { for testing. } \\
\text { This field } \\
\text { has a } \\
\text { severe } \\
\text { degree of } \\
\text { occlusion } \\
\text { compared } \\
\text { to the } \\
\text { others }\end{array}$ & $\begin{array}{c}\text { IoU } \\
\text { P- IoU } \\
(50) \\
\text { R-loU } \\
(50)\end{array}$ & $\begin{array}{c}0.64 \\
(\mathrm{IoU}), \\
86.6 \% \\
(\mathrm{P}-\mathrm{loU}), \\
46.3 \% \\
\text { (R-IoU) }\end{array}$ & $N / A$ & $\begin{array}{l}\text { (Dyrmann } \\
\text { Jørgense } \\
\text { n, \& } \\
\text { Midtiby, } \\
2017 \text { ) }\end{array}$ \\
\hline
\end{tabular}




\begin{tabular}{|c|c|c|c|c|c|c|c|c|c|c|c|c|c|c|}
\hline 33. & . & $\begin{array}{l}\text { Detecting } \\
\text { sugar beet } \\
\text { plants and } \\
\text { weeds in the } \\
\text { field based } \\
\text { on image } \\
\text { data }\end{array}$ & $\begin{array}{l}1,969 \text { RGB+NIR } \\
\text { images captured } \\
\text { using a JAI } \\
\text { camera in nadir } \\
\text { view placed on a } \\
\text { UAV. }\end{array}$ & $\begin{array}{l}\text { Identify if an } \\
\text { image patch } \\
\text { belongs to } \\
\text { weed or sugar } \\
\text { beet (image } \\
\text { region) }\end{array}$ & N/A & $\begin{array}{l}\text { Author- } \\
\text { defined } \\
\text { CNN }\end{array}$ & $\begin{array}{c}\text { TensorFI } \\
\text { ow }\end{array}$ & $\begin{array}{c}\text { Separated } \\
\text { vegetation/ } \\
\text { background } \\
\text { based on } \\
\text { NDVV, binary } \\
\text { mask to } \\
\text { describe } \\
\text { vegetation, } \\
\text { blob } \\
\text { segmentation, } \\
\text { resized to } \\
64 \times 64 \text { pix., } \\
\text { normalized } \\
\text { and centered }\end{array}$ & $\begin{array}{l}64 \text { even } \\
\text { rotations }\end{array}$ & $\begin{array}{c}\text { Same (also } \\
\text { generalized } \\
\text { to a second } \\
\text { dataset } \\
\text { produced 2- } \\
\text { weeks after, } \\
\text { at a more } \\
\text { advanced } \\
\text { growth } \\
\text { stage) }\end{array}$ & $P, R$ & $\begin{array}{c}\text { Dataset } \\
\text { A: } 97 \% \\
(\mathrm{P}), 98 \% \\
(\mathrm{R}) \\
\text { Dataset } \\
\text { B: } 99 \% \\
(\mathrm{P}), 89 \% \\
\text { (R) }\end{array}$ & $N / A$ & $\begin{array}{l}\text { (Milioto, } \\
\text { Lottes, \& } \\
\text { Stachniss } \\
, 2017 \text { ) }\end{array}$ \\
\hline 34. & 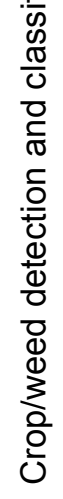 & $\begin{array}{l}\text { Detecting } \\
\text { and } \\
\text { classifying } \\
\text { sugar beet } \\
\text { plants and } \\
\text { weeds }\end{array}$ & $\begin{array}{l}\text { 1,600 4-channels } \\
\text { RGB+NIR images } \\
\text { captured before } \\
\text { (700 images) and } \\
\text { after (900 images) } \\
\text { a 4-week period, } \\
\text { provided by a } \\
\text { multispectral JAI } \\
\text { camera mounted } \\
\text { on a BOSCH } \\
\text { Bonirob farm } \\
\text { robot. }\end{array}$ & $\begin{array}{l}\text { Identifies if a } \\
\text { blob belongs to } \\
\text { sugar beet } \\
\text { crop, weeds or } \\
\text { soil (image } \\
\text { blob) }\end{array}$ & $\mathrm{N} / \mathrm{A}$ & $\begin{array}{l}\text { Author- } \\
\text { defined } \\
\text { CNN }\end{array}$ & $\begin{array}{c}\text { TensorFI } \\
\text { ow }\end{array}$ & \begin{tabular}{|l|} 
Pixel-wise \\
segmentation \\
between \\
green \\
vegetation \\
and soil based \\
on NDVI and \\
light CNN, \\
unsupervised \\
dataset \\
summariz.
\end{tabular} & N/A & $\begin{array}{c}\text { Same (also } \\
\text { generalized } \\
\text { to a second } \\
\text { dataset } \\
\text { produced 4- } \\
\text { weeks after, } \\
\text { at a more } \\
\text { advanced } \\
\text { growth } \\
\text { stage) }\end{array}$ & $\mathrm{CA}$ & $\begin{array}{c}98 \% \\
\text { (Dataset } \\
\text { A), } \\
59.4 \% \\
\text { (Dataset } \\
\text { B) }\end{array}$ & $\begin{array}{c}\text { Feature } \\
\text { extraction } \\
\text { (shape and } \\
\text { statistical } \\
\text { features) and } \\
\text { RF classifier: } \\
95 \%\end{array}$ & $\begin{array}{l}\text { (Potena, } \\
\text { Nardi, \& } \\
\text { Pretto, } \\
\text { 2016) }\end{array}$ \\
\hline
\end{tabular}




\begin{tabular}{|c|c|c|c|c|c|c|c|c|c|c|c|c|c|c|}
\hline 35. & & $\begin{array}{l}\text { Detecting } \\
\text { and } \\
\text { classifying } \\
\text { weeds and } \\
\text { maize in } \\
\text { fields }\end{array}$ & $\begin{array}{l}\text { Simulated top- } \\
\text { down images of } \\
\text { overlapping plants } \\
\text { on soil background } \\
\text { A total of } 301 \\
\text { images of soil and } \\
8,430 \text { images of } \\
\text { segmented plants. } \\
\text { The plants cover } \\
23 \text { different weed } \\
\text { species and } \\
\text { maize. }\end{array}$ & $\begin{array}{l}\text { Identifies if an } \\
\text { image patch } \\
\text { belongs to } \\
\text { weed, soil or } \\
\text { maize crop } \\
\text { (image pixel) }\end{array}$ & $\mathrm{N} / \mathrm{A}$ & $\begin{array}{c}\text { Adapted } \\
\text { version } \\
\text { of } \\
\text { VGG16 } \\
\text { CNN }\end{array}$ & $\begin{array}{l}\text { Develop } \\
\text { ed by } \\
\text { the } \\
\text { authors }\end{array}$ & $\begin{array}{c}\text { Image } \\
\text { cropping in } \\
800 \times 800 \text { pix. }\end{array}$ & $\begin{array}{c}\text { Random } \\
\text { scaling from } \\
80 \text { to } 100 \% \\
\text { of original } \\
\text { size, } \\
\text { random } \\
\text { rotations in } \\
\text { one degree } \\
\text { increments, } \\
\text { varied hue, } \\
\text { saturation } \\
\text { and } \\
\text { intensity, } \\
\text { random } \\
\text { shadows }\end{array}$ & $\begin{array}{l}\text { Tested on } \\
\text { real images } \\
\text { while } \\
\text { trained on } \\
\text { simulated } \\
\text { ones }\end{array}$ & $\begin{array}{l}\text { CA, } \\
\text { IoU }\end{array}$ & $\begin{array}{c}94 \% \text { CA, } \\
0.71 \mathrm{loU} \\
\text { (crops), } \\
0.70 \text { loU } \\
\text { (weeds) } \\
0.93 \text { loU } \\
\text { (soil) }\end{array}$ & $N / A$ & $\begin{array}{l}\text { (Dyrmann } \\
\text { Mortense } \\
\text { n, } \\
\text { Midtiby, \& } \\
\text { Jørgense } \\
\text { n, 2016) }\end{array}$ \\
\hline 36. & 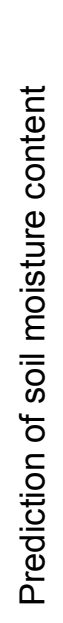 & $\begin{array}{l}\text { Predict the } \\
\text { soil moisture } \\
\text { content over } \\
\text { an irrigated } \\
\text { corn field }\end{array}$ & $\begin{array}{l}\text { Soil data collected } \\
\text { from an irrigated } \\
\text { corn field (an area } \\
\text { of } 22 \text { sq. km) in } \\
\text { the Zhangye oasis, } \\
\text { Northwest China. }\end{array}$ & $\begin{array}{l}\text { Percentage of } \\
\text { soil moisture } \\
\text { content (SMC) } \\
\text { (scalar value) }\end{array}$ & N/A & $\begin{array}{c}\text { Deep } \\
\text { belief } \\
\text { network- } \\
\text { based } \\
\text { macrosc } \\
\text { opic } \\
\text { cellular } \\
\text { automat } \\
\text { a (DBN- } \\
\text { MCA) }\end{array}$ & $\begin{array}{l}\text { Develop } \\
\text { ed by } \\
\text { the } \\
\text { authors }\end{array}$ & $\begin{array}{c}\text { Geospatial } \\
\text { interpolation } \\
\text { for creation of } \\
\text { soil moisture } \\
\text { content maps, } \\
\text { multivariate } \\
\text { geostatistical } \\
\text { approach for } \\
\text { estimating } \\
\text { thematic soil } \\
\text { maps, maps } \\
\text { converted to } \\
\text { TIFF, } \\
\text { resampled to } \\
\text { 10-m res. }\end{array}$ & $\mathrm{N} / \mathrm{A}$ & Same & RMSE & 6.77 & $\begin{array}{l}\text { Multi-layer } \\
\text { perceptron } \\
\text { MCA (MLP- } \\
\text { MCA): } 18 \% \\
\text { reduction in } \\
\text { RMSE }\end{array}$ & $\begin{array}{l}\text { (Song, et } \\
\text { al., 2016) }\end{array}$ \\
\hline
\end{tabular}




\begin{tabular}{|c|c|c|c|c|c|c|c|c|c|c|c|c|c|c|}
\hline 37. & & $\begin{array}{l}\text { Practical and } \\
\text { accurate } \\
\text { cattle } \\
\text { identification } \\
\text { from } 5 \\
\text { different } \\
\text { races }\end{array}$ & $\begin{array}{l}1,300 \text { images } \\
\text { collected by the } \\
\text { authors. }\end{array}$ & $\begin{array}{l}5 \text { classes: } \\
\text { Cattle races, } \\
\text { Bali } \\
\text { Onggole or } \\
\text { Pasuruan, } \\
\text { Aceh } \\
\text { Madura and } \\
\text { Pesisir }\end{array}$ & N/A & $\begin{array}{l}\text { GLCM - } \\
\text { CNN }\end{array}$ & $\begin{array}{l}\text { Deep } \\
\text { Learning } \\
\text { Matlab } \\
\text { Toolbox }\end{array}$ & \begin{tabular}{|c|} 
GLCM \\
features \\
extraction \\
(contrast, \\
energy and \\
homogeneity), \\
saliency maps \\
to accelerate \\
feature \\
extraction
\end{tabular} & $N / A$ & Same & CA & $93.76 \%$ & $\begin{array}{l}\text { CNN without } \\
\text { extra inputs: } \\
89.68 \% \\
\text { Gaussian } \\
\text { Mixture } \\
\text { Model } \\
\text { (GMM): } 90 \%\end{array}$ & $\begin{array}{l}\text { (Santoni, } \\
\text { Sensuse, } \\
\text { Arymurth } \\
\text { y, \& } \\
\text { Fanany, } \\
\text { 2015) }\end{array}$ \\
\hline 38. & & $\begin{array}{l}\text { Predict } \\
\text { growth of } \\
\text { pigs }\end{array}$ & $\begin{array}{l}160 \text { pigs, housed } \\
\text { in two climate } \\
\text { controlled rooms, } \\
\text { four pens/room, } 10 \\
\text { pigs/pen. } \\
\text { Ammonia, ambient } \\
\text { and indoor air } \\
\text { temperature and } \\
\text { humidity, feed } \\
\text { dosage and } \\
\text { ventilation } \\
\text { measured at 6- } \\
\text { minute intervals. }\end{array}$ & $\begin{array}{l}\text { Estimation of } \\
\text { the weight of } \\
\text { pigs (scalar } \\
\text { value) }\end{array}$ & $N / A$ & $\begin{array}{l}\text { First- } \\
\text { order } \\
\text { DRNN }\end{array}$ & $\begin{array}{l}\text { Develop } \\
\text { ed by } \\
\text { the } \\
\text { authors }\end{array}$ & $\mathrm{N} / \mathrm{A}$ & $\mathrm{N} / \mathrm{A}$ & $\begin{array}{l}\text { Tested on } \\
\text { different } \\
\text { rooms of } \\
\text { pigs than } \\
\text { the ones } \\
\text { which were } \\
\text { used for } \\
\text { training }\end{array}$ & $\begin{array}{l}\text { MSE, } \\
\text { MRE }\end{array}$ & $\begin{array}{c}0.002 \\
\text { (MSE) on } \\
\text { same } \\
\text { dataset), } \\
10 \% \\
\text { (MRE) in } \\
\text { relation to } \\
\text { a } \\
\text { controller }\end{array}$ & $N / A$ & $\begin{array}{l}\text { (Demmer } \\
\text { s T. G., } \\
\text { Cao, } \\
\text { Parsons, } \\
\text { Gauss, \& } \\
\text { Wathes, } \\
\text { 2012) }\end{array}$ \\
\hline 39. & 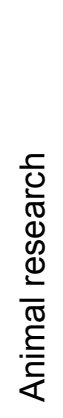 & $\begin{array}{l}\text { Control of } \\
\text { the growth of } \\
\text { broiler } \\
\text { chickens }\end{array}$ & $\begin{array}{l}\text { Collecting data } \\
\text { from } 8 \text { rooms, } \\
\text { each room } \\
\text { housing } 262 \\
\text { broilers, } \\
\text { measuring bird } \\
\text { weight, feed } \\
\text { amount, light } \\
\text { intensity and } \\
\text { relative humidity. }\end{array}$ & $\begin{array}{l}\text { Estimation of } \\
\text { the weight of } \\
\text { chicken (scalar } \\
\text { value) }\end{array}$ & N/A & $\begin{array}{l}\text { First- } \\
\text { order } \\
\text { DRNN }\end{array}$ & $\begin{array}{l}\text { Develop } \\
\text { ed by } \\
\text { the } \\
\text { authors }\end{array}$ & $\mathrm{N} / \mathrm{A}$ & $\mathrm{N} / \mathrm{A}$ & $\begin{array}{l}\text { Tested on } \\
\text { different } \\
\text { rooms of } \\
\text { chicken } \\
\text { than the } \\
\text { ones which } \\
\text { were used } \\
\text { for training }\end{array}$ & $\begin{array}{l}\text { MSE, } \\
\text { MRE }\end{array}$ & $\begin{array}{c}0.02 \\
(\mathrm{MSE}) \\
1.8 \% \\
(\mathrm{MRE}) \text { in } \\
\text { relation to } \\
\mathrm{a} \\
\text { controller }\end{array}$ & $N / A$ & $\begin{array}{l}\text { (Demmer } \\
\text { s T. G., et } \\
\text { al., 2010) }\end{array}$ \\
\hline
\end{tabular}




\begin{tabular}{|c|c|c|c|c|c|c|c|c|c|c|c|c|c|c|}
\hline 40. & 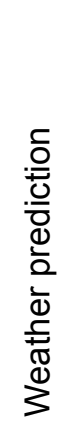 & $\begin{array}{l}\text { Predict } \\
\text { weather } \\
\text { based on } \\
\text { previous } \\
\text { year's } \\
\text { conditions }\end{array}$ & $\begin{array}{l}\text { Syngenta Crop } \\
\text { Challenge } 2016 \\
\text { dataset, containing } \\
6,490 \text { sub-regions } \\
\text { with three weather } \\
\text { condition attributes } \\
\text { from the years } \\
2000 \text { to } 2015 \text {. }\end{array}$ & $\begin{array}{l}\text { Predicted } \\
\text { values of } \\
\text { temperature, } \\
\text { precipitation } \\
\text { and solar } \\
\text { radiation } \\
\text { (scalar value) }\end{array}$ & $\mathrm{N} / \mathrm{A}$ & LSTM & Keras & $\mathrm{N} / \mathrm{A}$ & $\mathrm{N} / \mathrm{A}$ & Same & $\begin{array}{c}\text { N- } \\
\text { RMSE, } \\
\text { MRE }\end{array}$ & \begin{tabular}{|c|}
$78 \%$ \\
(Temperat \\
ure), 73\% \\
(Precipitati \\
on), 2.8\% \\
(Solar \\
Radiation) \\
N-RMSE, \\
$1-3 \%$ \\
MRE in all \\
categories
\end{tabular} & $\mathrm{N} / \mathrm{A}$ & $\begin{array}{l}\text { (Sehgal, } \\
\text { et al., } \\
2017 \text { ) }\end{array}$ \\
\hline
\end{tabular}


Appendix III: Publicly-available datasets related to agriculture.

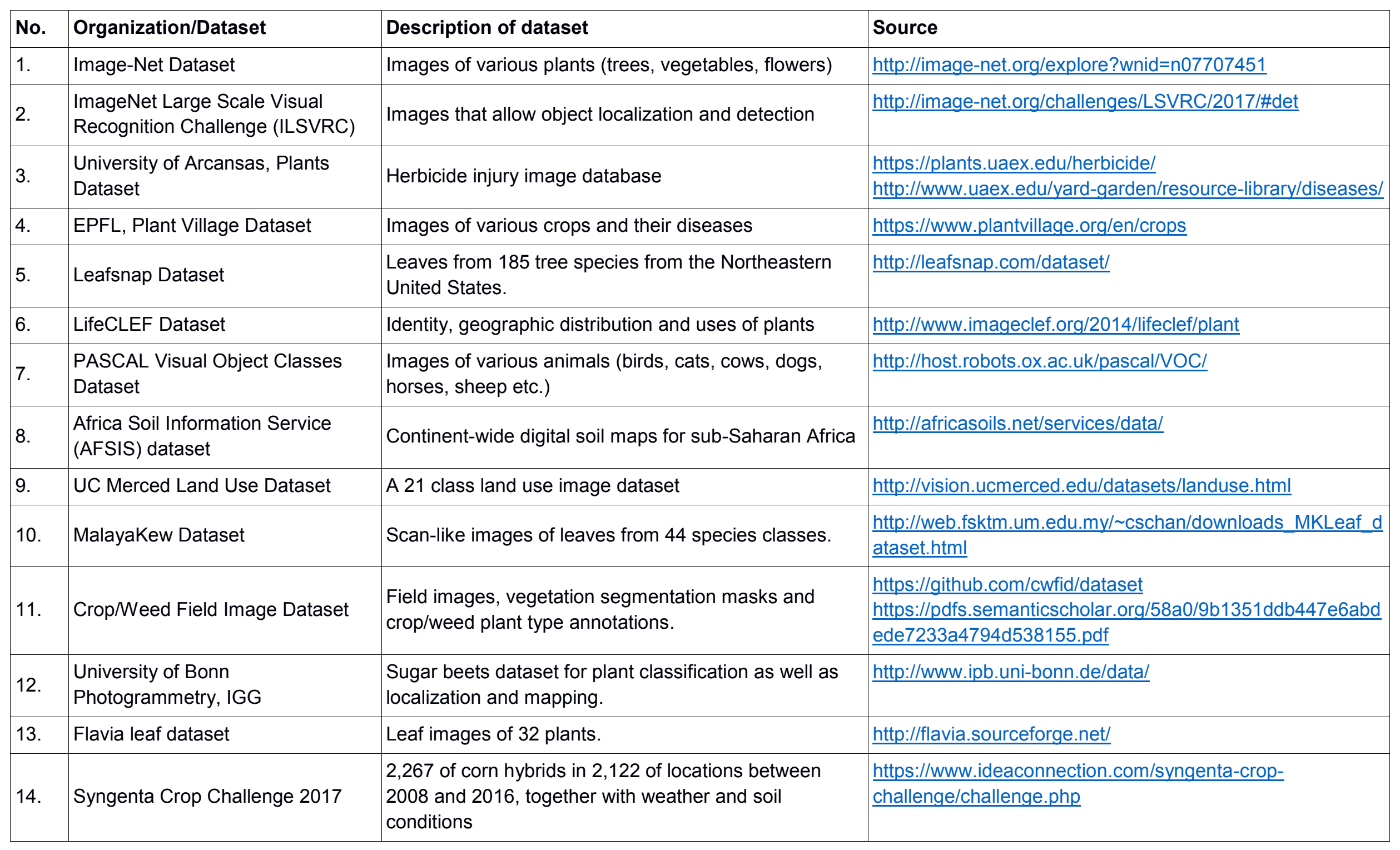

